\title{
Investigation of the atmospheric boundary layer dynamics during the ESCOMPTE campaign
}

\author{
F. Saïd ${ }^{1}$, A. Brut ${ }^{2}$, B. Campistron ${ }^{1}$, and F. Cousin ${ }^{3}$ \\ ${ }^{1}$ Centre de Recherches Atmosphériques, UMR CNRS 5560, 8 route de Lannemezan, 65300 Campistrous, France \\ ${ }^{2}$ Centre d'Etudes Spatiales de la BIOsphère UMR 5126, 18 avenue Edouard Belin, 31401 Toulouse Cedex 9, France \\ ${ }^{3}$ Laboratoire d'Aérologie, UMR CNRS 5560, 14 avenue Edouard Belin, 31400 Toulouse, France
}

Received: 25 April 2005 - Revised: 7 February 2007 - Accepted: 27 February 2007 - Published: 29 March 2007

\begin{abstract}
This paper presents some results about the behavior of the atmospheric boundary layer observed during the ESCOMPTE experiment. This campaign, which took place in south-eastern France during summer 2001, was aimed at improving our understanding of pollution episodes in relation to the dynamics of the lower troposphere. Using a large data set, as well as a simulation from the mesoscale nonhydrostatic model Meso-NH, we describe and analyze the atmospheric boundary layer (ABL) development during two specific meteorological conditions of the second Intensive Observation Period (IOP). The first situation (IOP2a, from 22 June to 23 June) corresponds to moderate, dry and cold northerly winds (end of Mistral event), coupled with a seabreeze in the lower layer, whereas sea-breeze events with weak southerly winds occurred during the second part of the period (IOP2b, from 24 June to 26 June).
\end{abstract}

In this study, we first focus on the validation of the model outputs with a thorough comparison of the Meso-NH simulations with fields measurements on three days of the IOP: 22 June, 23 June and 25 June. We also investigate the structure of the boundary layer on IOP2a when the Mistral is superimposed on a sea breeze. Then, we describe the spatial and diurnal variability of the ABL depths over the ESCOMPTE domain during the whole IOP. This step is essential if one wants to know the depth of the layer where the pollutants can be diluted or accumulated. Eventually, this study intends to describe the $\mathrm{ABL}$ variability in relation to local or mesoscale dynamics and/or induced topographic effects, in order to explain pollution transport processes in the low troposphere.

Keywords. Atmospheric composition and structure (Pollution - urban arid regional; Troposphere - composition and chemistry) - meteorology and atmospheric dynamics (Mesoscale meteorology)

Correspondence to: A. Brut

(aurore.brut@cesbio.cnes.fr)

\section{Introduction}

Prediction of pollution events and implementation of adapted air quality policies require a considerable improvement in the understanding of chemical and dynamical processes which lead to high pollutant concentrations in the atmosphere. Peculiar attention must be paid to the processes which take place in coastal zones, where cities and industries often concentrate. In addition, coastal regions are also subject to wind circulations that are both synoptically induced and localized, or diurnal and terrain-induced (Rosenthal et al., 2003; Angevine et al., 2004).

The Mediterranean basin in Europe is surrounded by high coastal mountains while it is heavily urbanized and industrialized. The meteorological processes in summer are dominated by the Azores anticyclone, situated in south-western Europe and characterized by warm temperatures and moderate winds favorable to the onset of sea-breeze circulations. Several European projects have been conducted around the Mediterranean basin to document the circulation of air pollutants: among them are the MEso-meteorological Cycles of Air Pollution in the Iberian Peninsula, MECAPIP, 19881991 (Millàn et al., 1996, 2000), the REgional Cycles of Air Pollution in the west-central Mediterranean Area, RECAPMA, 1990-1992 (Gangoiti et al., 2001) and the South European Cycles of Air Pollution, SECAP, 1992-1995 (Millàn et al., 1997). These experimental projects showed that during daytime and summer conditions, the combination of sea breezes with up-slope winds, due to the strong heating on the mountains, may inject pollutants up to the low $(2-3 \mathrm{~km})$ or even middle troposphere $(3-5 \mathrm{~km})$, forming an accumulation of ozone layers over the continent. This aged pollution travels at upper levels and may come back down to the sea or to the coastal areas, through subsidence processes, such as the compensatory return flow of the up-slope and sea-breeze circulations. These scenarios are likely to occur in the area selected for the European campaign ESCOMPTE "Expérience sur Site pour CONtraindre

Published by Copernicus GmbH on behalf of the European Geosciences Union. 
les Modèles de Pollution atmosphérique et de Transport d'Emissions" (Cros et al., 2004), which took place between the beginning of June 2001 and mid-July 2001. The specificity of this project, in comparison with the previous ones, was to reinforce the experimental as well as the numerical frame. The main objective of the ESCOMPTE experiment was indeed to establish a detailed three-dimensional database of primary pollutant emissions, together with the dynamics and chemical composition of the atmosphere, in order to validate and improve numerical modeling of chemistry and transport. A $120 \times 120 \mathrm{~km}$ area centered on the coastal city of Marseille and the Berre pond, one of the most polluted region in France, was selected to host the experiment. This region presents high occurrences of photochemical pollution events due to its dense industrialization and urbanization, combined with the hot and sunny weather conditions of summertime. The transport of the plumes is also highly influenced by the characteristics of topography and subject to secondary circulation systems, such as land/sea-breeze, slope winds and valley-mountain winds. Thus, the second Intensive Observation Period (IOP2) of the ESCOMPTE campaign that lasted from 22 June to 26 June (hereafter identified as J22 to J26) was selected for the present study since the level of pollution was the highest of the experiment. During this period, a large amount of aircraft, radars and radio-soundings measurements was available. Using this large data set, in addition to numerical simulations, we intended to investigate the meteorological processes which affect the atmospheric concentration of pollutants (accumulation, dispersion and transport). These features include the development and thickness of the Atmospheric Boundary Layer (hereafter, ABL) and the effect of mesoscale circulation. Our analysis of atmospheric dynamics is mainly focused on two kinds of typical meteorological conditions that occurred in south-eastern France: just before J22, a strong northerly regional wind called Mistral had been blowing in the Rhone valley. It weakened on J22 and J23 which enabled the sea breeze to impact the lower layers near the coast. Guénard et al. (2005) showed that during the daytime, the coastal Mistral was affected by the sea breeze and by thermally driven convection which could lift up the Mistral above $2 \mathrm{~km}$. This is consistent with our results, although we observe that the boundary layer development is rather different over the region for these two days.

After that, the meteorological situation turned to weak southerly winds with a diurnal sea-breeze circulation from J24 to J26. For these typical conditions, differences appeared on the spatial and temporal variability of the ABL, therefore influencing the possibilities of exchanges between the ABL and the free troposphere.

The present paper is organized as follows: the instrumental set-up and data processing are presented in Sect. 2. Section 3 proposes a brief description of the meteorological conditions observed during the two periods of IOP2. In Sect. 4, simulation and experimental results of IOP2 are compared. It is also an opportunity to point out different behaviors of the ABL development between J22 and J23 (both days corresponding to a situation of Mistral wind combined with a weak sea breeze near the coast) and to detail a pure sea-breeze case (J25). Section 5 addresses a point of major interest which concerns the variability of the depth of the ABL, since it impacts the layer where pollutants are likely to dilute or accumulate. Finally, we describe in Sect. 6 the resulting fields of ozone concentration and comment on them in light of the previous results.

\section{Data and tools}

The wide instrumental set-up deployed over the region was designed to document dynamics as well as chemistry, including aerosols. For the present work, we used meteorological and chemical measurements collected on board three airplanes. In addition, three-dimensional fields of the wind components were provided by a profiler network of UHF radars, and vertical profiles of meteorological parameters were obtained from radio-soundings launched from several places over the area. The location of the various instrumental sites is shown on Fig. 1.

The complex topography of the region has to be noticed. As the region is situated at the foothill of the Alps (a large and high ridge exceeding $3000 \mathrm{~m}$ ), several mountainous massifs whose altitudes can reach $1000 \mathrm{~m}$ are encountered in the eastern and northern parts of the domain. To the west, the Crau plain and the wide Rhône valley (north-south orientation) correspond to flat and low terrain, except for the 450$\mathrm{m}$ high Alpilles ridge which crosses the Rhône valley. To the north, the Apt and Durance valleys are narrow channels that sink into the mountains: the Durance valley is first oriented north-east/south-west (Vinon-Cadarache-Pertuis) and then bends towards a west-east direction, parallel to the Apt valley, but on the other side of the Luberon massif. In addition to this complex topography, the presence of the sea to the south is another factor which will play a role in local circulations.

\subsection{UHF wind-profilers}

The wind profilers network is made up of four Ultra High Frequency (UHF) radars (DEGREWIND PCL1300) located in Saint Chamas, Marignane, Aix-les-Milles and Marseille. The profilers have the same technical features: a 4-kW peakpower, a 1238-MHz transmitted frequency and a 150-m pulse width. Except for the profiler installed at Aix-les-Milles, which only used three beams, the profilers operated with five beams. One beam is vertical and the others are disposed every $90^{\circ}$ in azimuth with a $77^{\circ}$ elevation angle. The wind profilers provided vertical profiles every five minutes of the three wind velocity components, the reflectivity and the Doppler spectral width, from $75 \mathrm{~m}$ above ground level (AGL) up to 2 or $3 \mathrm{~km}$, depending on atmospheric conditions, with a $75-\mathrm{m}$ 
vertical resolution. The meteorological peak in the Doppler spectra is selected according to a 30-min duration consensus technique, mainly based on thresholds, vertical and temporal continuity. More details on the data processing, radar techniques and signal scattering can be found in Jacoby-Koaly et al. (2002) and Puygrenier et al. (2005). In addition to the basic measurements of the wind profilers, the turbulent kinetic energy dissipation rate $\varepsilon$ can be deduced from the UHF Doppler spectral width and reflectivity is proportional to the air refractive index structure coefficient $C_{n}^{2}$. Local maxima of this coefficient are usually associated with the atmospheric boundary layer top, $Z_{i}$, resulting from high vertical gradients of temperature and humidity and strong turbulent mixing. Then, the height-time section of the structure coefficient $C_{n}^{2}$ enables one to follow the daytime ABL development with the accuracy of the $Z_{i}$ measurement being of the order of half the radar pulse length $(75 \mathrm{~m}$ ) (Angevine et al., 1994; Heo et al., 2003).

So, profilers that worked continuously during the whole campaign were an essential tool in the determination of the temporal variation of the ABL top, whereas radiosounding and aircraft vertical profiles could only provide sparse observations.

\subsection{Aircraft}

To fulfill the ESCOMPTE objectives and to provide measurements on a regional scale, three airplanes equipped with instrumentation flew three times a day, following five horizontal and parallel legs along a west-east direction, at the constant level of $800 \mathrm{~m}$ (Fig. 1). The Fokker 27 ARAT from the Institut National des Sciences de 1'Univers (INSU) flew at 05:00 and 11:00 UTC, whereas the Dornier 128 from the Institut für Meteorologie und Klimaforschung (IMK) flew in the early afternoon at 14:00 UTC. An exception occurred on J22, when the morning flights at 05:00 and 11:00 UTC were performed by the Merlin 4 from Météo-France and the Dornier 128, respectively, and no flight was operated in the afternoon. The three airplanes measured classical meteorological parameters, radiative fluxes and trace gases $\left(\mathrm{O}_{3}\right.$, $\left.\mathrm{CO}, \mathrm{NO}_{\mathrm{x}}\right)$ at a sampling rate of $1 \mathrm{~Hz}$. Turbulence measurements were recorded at a sampling frequency of $25 \mathrm{~Hz}$ on the Dornier and Merlin and $16 \mathrm{~Hz}$ on the Fokker. More details about the aircraft instrumentation can be found in Saïd et al. (2005). These "exploration" flights allowed us to retrieve two-dimensional maps of chemical and meteorological variables over the region, using a kriging method.

Spatial interpolation is rather tricky when dealing with meteorological data measured over complex terrain. The kriging technique was used to provide fields of various parameters measured on board aircraft, at the flight level. It is a so-called optimal interpolation method which predicts interpolated values from data observed at discrete locations (Matheron G., 1963). We used the Matlab kriging toolbox 3.0, developed by Lafleur and Gratton (1998) and almost en-

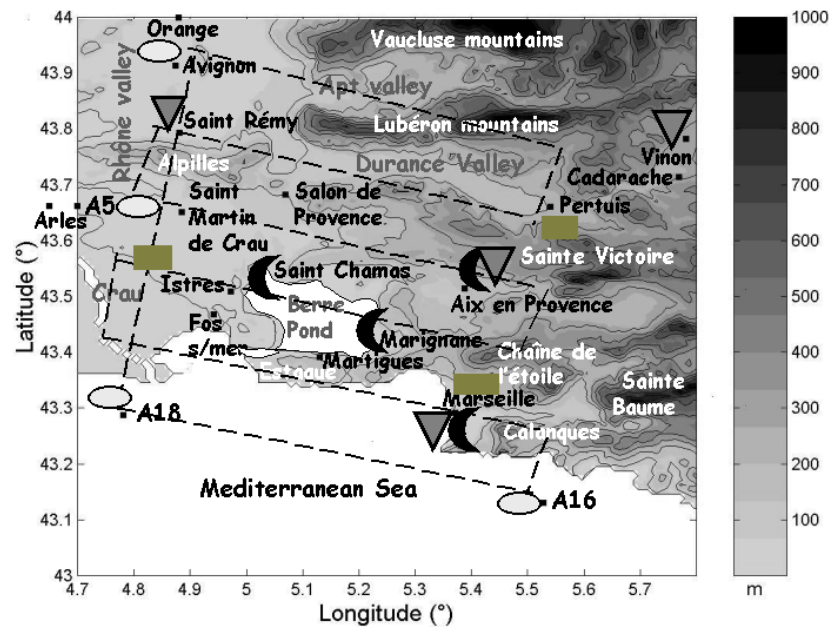

Fig. 1. Map of the various instrumented sites and horizontal track of the flights performed by the aircraft during the ESCOMPTE field experiment. Ellipses represent aircraft sounding locations. Triangles indicate radio-sounding sites and black half-moons correspond to the location of UHF wind profilers. Grey rectangles indicate the surface flux stations. Names of town, mountains and valleys are written in black, white and grey, respectively.

tirely written from functions proposed by Deutsch and Journel (1992) and Marcotte (1991). The spatial length scale resolved by this interpolation method is about $12 \mathrm{~km}$ which corresponds to the distance between two parallel flight legs and thus allows a reasonable interpolation of the data in both directions (parallel and perpendicular to the flight legs). In addition, the standard deviation of the calculated fields yields information on the estimated error of the interpolated distribution pattern (Kalthoff et al., 2005). In our case, the standard deviation for all fields is weaker than $10 \%$ and highlights the reasonable accuracy of the method.

The turbulent kinetic energy (TKE) dissipation rate $\varepsilon$ turned out to be useful for this study, since it helped to discriminate between the ABL and the free troposphere: turbulence is strong within the ABL and close to zero in the free troposphere. Temperature and humidity were used to find a threshold for $\varepsilon$, using vertical profiles of the three parameters. The TKE dissipation rate $\varepsilon$ can vary over several orders of magnitude which is not the case in thermodynamics. In addition, a spatial increase in potential temperature (or decrease in humidity) may be due to a horizontal gradient, as well as to a change in the vertical layer, so thermodynamics can hardly be used to discriminate between ABL and the free troposphere. We plotted fields of $\log (\varepsilon)$ and observed that the spatial variability of TKE showed sharp transitions. Then, combining these fields of TKE with the temperature and water vapor fields allows one to determine whether the aircraft flew within or above the ABL.

$\varepsilon$ was computed using a method described in Shaw and Businger (1985) and Lambert and Durand (1999). It 
consisted of band-pass filtering the time series of the vertical velocity component, in order to keep only the signal frequencies involved in the inertial subrange. The vertical velocity was filtered in the wavelength range $6 \mathrm{~m}$ to $100 \mathrm{~m}$. $\varepsilon$ was then computed from this signal on short overlapping segments of $3 \mathrm{~km}$, which corresponds to the model resolution.

\subsection{Radiosoundings}

Four sites were equipped with rawinsonde systems (Fig. 1). Two rawinsonde systems were operated by IMK every $3 \mathrm{~h}$ from 08:00 to 20:00 UTC: one was located in the northeastern part of the domain, at Vinon in the Durance valley, the second one was at Saint Rémy, close to the northwestern ridge Les Alpilles. At Aix-les-Milles, in the central part of the ESCOMPTE domain, the Centre National de la Recherche Atmosphérique (CNRM) also launched two radiosoundings per day between 06:00 and 17:00 UTC, with ozone profile abilities once a day. Furthermore, in the context of the Urban Boundary Layer (UBL) program (Mestayer et al., 2005), a rawinsonde system provided occasional measurements of temperature and moisture profiles at the Observatoire in the Marseille city center.

\subsection{Ground-based stations}

We also used data from three ground-based stations which provided measurements of standard meteorological variables (air temperature, mean wind speed, humidity, etc....) and flux estimates every $30 \mathrm{~min}$. One of the stations was installed in Meyrargues $\left(43.65^{\circ} \mathrm{N}, 5.5^{\circ} \mathrm{E}\right)$, in the Durance valley. Measurements were carried out above a maize field. A complete description of the site can be found in Brut et al. (2004). The sites of Vallon d'Ol $\left(43.35^{\circ} \mathrm{N}, 5.40^{\circ} \mathrm{E}\right)$, on Marseille foothills and $\mathrm{La}$ Crau, in the plain near Arles $\left(43.57^{\circ} \mathrm{N}, 4.82^{\circ} \mathrm{E}\right)$ corresponded to bare soil. The instrumentation implemented on these sites is described in Cros et al. (2004). These measurements sites are located in Fig. 1.

\subsection{Complementary modelling}

To further analyze study cases of IOP2, the threedimensional mesoscale model Meso-NH was used. This model is a non-hydrostatic model, jointly developed by the Laboratoire d'Aérologie (CNRS) and the CNRM (MétéoFrance) (Lafore et al., 1998). The chemical modules are coupled online with Meso-NH, which means that the meteorological and chemical fields (Suhre et al., 1998) are simultaneously computed at each time step and each grid point. In our case, we used the gas-phase chemical module ReLACS (Crassier et al., 2000). The Genemis anthropogenic emission inventory (Wickert et al., 1999) at 9-km resolution was used. Two-way grid nested simulations were carried out and provided two grids of resolution, $3 \mathrm{~km}$ and $9 \mathrm{~km}$, centered on Marseille and Berre Pond. The domain of interest (the smaller) is located between latitudes $42.7^{\circ} \mathrm{N}$ and $44.3^{\circ} \mathrm{N}$, and longitudes $4.22^{\circ} \mathrm{E}$ and $6.42^{\circ} \mathrm{E}$. There are 54 vertical levels, among which 40 lie between the surface and $2500 \mathrm{~m}$. The simulation started at 00:00 UTC, on J21. The description of the model configuration for the simulation can be found in Cousin et al. (2005).

\section{Description of IOP2}

IOP2 (22 June 2001-26 June 2001) of the ESCOMPTE campaign is divided into two periods (hereafter IOP2a and IOP2b), with significant changes in the meteorological situation on J23 around 17:00 UTC (Cros et al., 2004). IOP2a includes $\mathbf{J} 22$ and 23 and it corresponds to the end of a Mistral episode, i.e. moderate north-west wind. The IOP2b (24 June 2001-26 June 2001) corresponded to a different airflow situation, dominated by the sea breeze which best characterized a pollution event. In this section, we briefly recall the meteorological situations encountered during these five days.

The synoptic conditions observed from J22 to J23 consisted of a north-west regime at $500 \mathrm{hPa}$ with a ridge from Gibraltar to Ireland and an extended $1013 \mathrm{hPa}$ isobar over the Mediterranean Sea. This resulted in a case of Mistral, a northerly low-level wind induced by orography. This characteristic outbreak of south-eastern France often brings cold and dry continental air masses and restores clear sky conditions after the passage of a cold front. A complete description of the Mistral events that occurred during ESCOMPTE, as well as its interaction with the sea breeze or its effect on air pollution transport can be found in Guénard et al. (2005), Bastin et al. (2006) and Corsmeier et al. (2005).

On J22, the weather was fair with a clear sky. Temperatures which were around 21 to $23^{\circ} \mathrm{C}$ in the morning, reached maxima of 31 to $33^{\circ} \mathrm{C}$ in the afternoon. The wind was weak and coming from the northeast at the beginning of the day. In the early afternoon, a thermal breeze settled in the lower layer near the coast while the flow remained from the northwest inland.

On J23, the weather was still sunny and hot temperatures were observed with a maximum of 30 to $32^{\circ} \mathrm{C}$ over the whole region. In the morning, a weak north-westerly wind blew all day long over the region, except in the western part of the domain where it was stronger $\left(5.1-7.7 \mathrm{~m} \mathrm{~s}^{-1}\right)$. In the afternoon, the sea breeze set up around 16:00 UTC and extended along the coast.

On IOP2b, western Europe was under the influence of a high pressure system centred over the Netherlands. Pressure gradients were weak over the whole of central Europe (Kalthoff et al., 2005). In fact, there was a complex interaction between synoptic northerly winds and local circulations; these conditions favoured both the evolution of mesoscale circulation systems and the evolution of a summer smog situation (Vogel et al., 1995).

On J24, the sky was clear from early morning: temperatures were about $18^{\circ} \mathrm{C}$ in the western part of the domain and 
$15^{\circ} \mathrm{C}$ in the east. They increased up to $28^{\circ} \mathrm{C}$ and $30^{\circ} \mathrm{C}$ in the afternoon. Between $500 \mathrm{~m}$ and $1500 \mathrm{~m}$ we observed a moderate flow from the northwest (5.1 to $7.7 \mathrm{~m} \mathrm{~s}^{-1}$ ) which weakened and veered from the west-northwest. In the lower layers, the sea breeze set-up along the coast and then extended inland with a south-west direction and a moderate strength (5.1 to $7.7 \mathrm{~m} \mathrm{~s}^{-1}$ ). This sea-breeze day was also described and studied by Cousin et al. (2005).

On J25, an anticyclonic cell is located in the North Sea with an extension towards the Mediterranean basin: this induced a weak wind regime, dominated by a sea breeze. Since 07:00 UTC, a southerly wind has been observed near the coast, due to a sea-breeze effect; around 15:00 UTC, the seabreeze has spread over the whole region. In addition, the sky remained clear with a few altocumulus clouds and temperatures from $26^{\circ} \mathrm{C}$ to $28^{\circ} \mathrm{C}$ near the coast and 31 to $34^{\circ} \mathrm{C}$ inland.

On J26, a weak pressure gradient at the surface induced a breeze regime. A southerly breeze rapidly replaced the weak to moderate morning wind from the east to the southeast, especially in the Rhône valley, whereas it was from the southwest in the eastern area. Eventually, the temperatures were about the same as the day before and a few altocumulus clouds were present in the sky.

Additional information and illustrations can be found in Bastin et al. (2005a) and Kalthoff et al. (2005) for J25 and J26, and in Delbarre et al. (2005) for J26.

\section{Comparisons between modeling and experimental data at 2 levels}

In this section, we compare the numerical simulations provided by the MesoNH model with experimental data at two heights in the ABL (the surface and the $800 \mathrm{~m}$ level) on several days of IOP2.

\subsection{Sea-breeze and Mistral on 22 and 23 June}

The interactions between the sea breeze and Mistral have already been studied in other publications (Bastin et al., 2006, 2005a, b; Caccia et al., 2005), whose authors focused mainly on $\mathrm{J} 22$.

Comparison between modelling and measurements at the surface and at the 800-m level

Time series of temperature, water vapor mixing ratio and wind speed and direction are displayed in Fig. 2, for J22 at the three ground sites (La Crau plain, Vallon d'Ol and Meyrargues). The distance of the three ground stations to the closest coastline is about 30,10 and $40 \mathrm{~km}$, respectively. The sea breeze is usually detected through a diurnal veering of the synoptic wind, which is accompanied by a temperature decrease and moisture increase. The onset times are represented by an arrow on the figures and are summed up in Ta-
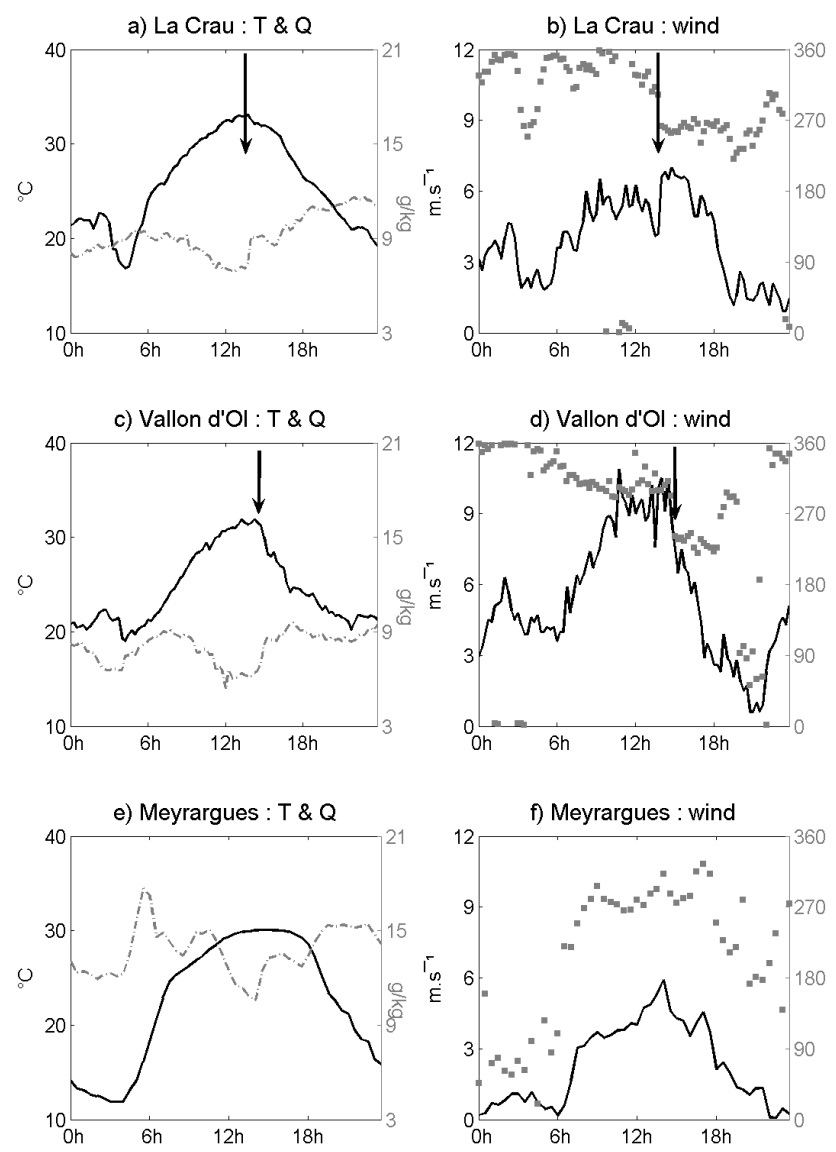

Fig. 2. Time series of meteorological parameters measured on 22 June above bare soil in the plain of La Crau (a and b), in Vallon d'Ol in the northern suburb of Marseille (c and $\mathbf{d}$ ) and above a maize field in Meyrargues (e and f). On the left, the air temperature is represented with a solid black line and the water vapour mixing ratio with a dashed grey line. On the right-hand figures, the wind speed is represented with a solid black line, whereas the wind direction is represented with grey squares. The black arrows indicate the seabreeze onset.

ble 1. So, the sea breeze reaches La Crau around 14:00 UTC and persists until 19:00 UTC. The sea breeze reaches Vallon d'Ol around 14:30 UTC when the wind and the temperature decrease while the humidity rate increases. This slight delay between the two sites is consistent with the observations of Bastin et al. (2006) but is not linked to the distance to the coastline. No sea breeze is detected in Meyrargues: the wind is from the northwest and corresponds to the Mistral. The potential temperature diurnal cycle is bell-shaped, like a classical surface layer over such a ground cover, whereas it is sharper in the two previous cases. The humidity cycles are very different over the three sites: in La Crau, we observe the usual humidity increase due to the sea-breeze onset. In Vallon d'Ol, the humidity decreases between 09:00 and 15:00 UTC and increases again with the sea-breeze onset. In Meyrargues, the humidity variability is also related 
Table 1. Sea-breeze onset time (UTC) detected at the three ground stations/with the model for the whole period.

\begin{tabular}{llllll}
\hline Ground station & 22 June & 23 June & 24 June & 25 June & 26 June \\
\hline La Crau & $14: 00 / 14: 00$ & $15: 30 /-$ & $09: 00 / 09: 00$ & $07: 00 / 09: 00$ & $07: 30 / 07: 30$ \\
Vallon D'ol & $14: 30 / 15: 00$ & $11: 00 /-$ & $07: 00 / 09: 00$ & $08: 30 / 09: 00$ & $07: 00 / 08: 00$ \\
Meyrargues & $-/$ & $17: 00 /-$ & $12: 00 / 12: 00$ & $10: 00 / 12: 00$ & $13: 30 / 13: 00$ \\
\hline
\end{tabular}

Meso-NH simulations on June 22, 1200 UTC
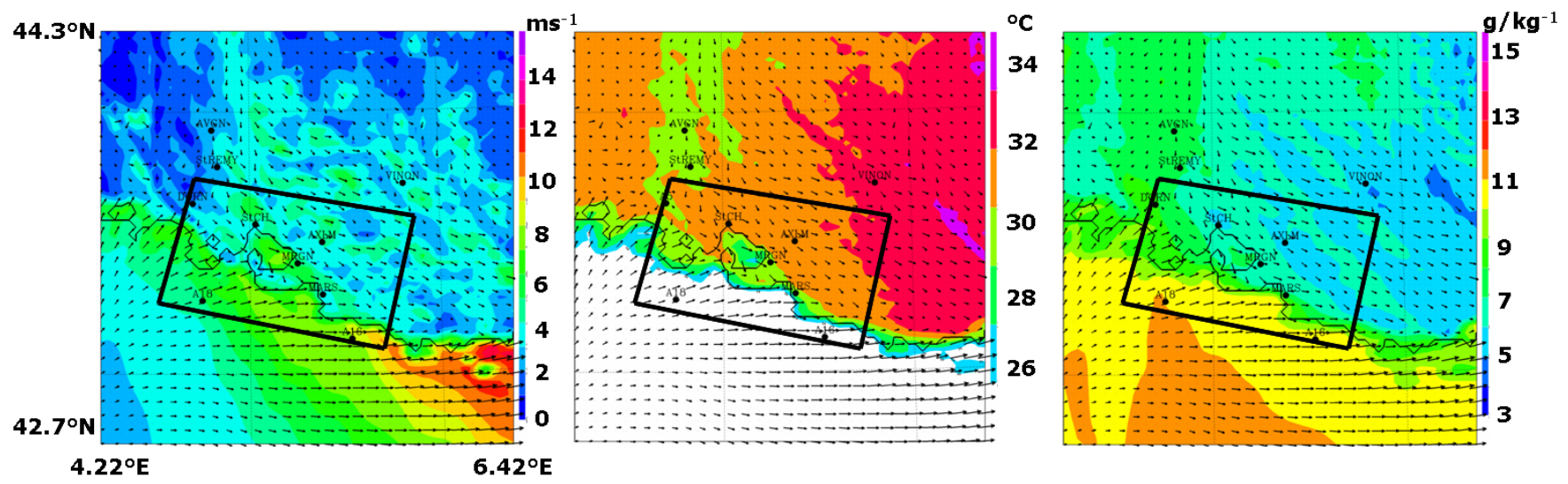

a) Wind field at the surface

b) Potential temperature at the surface

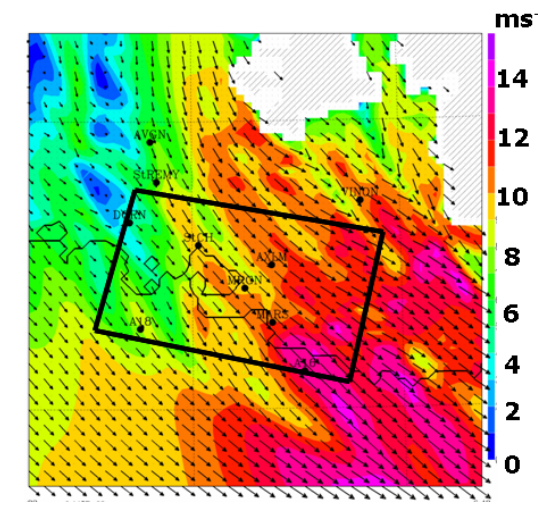

d) Wind field at $800 \mathrm{~m}$

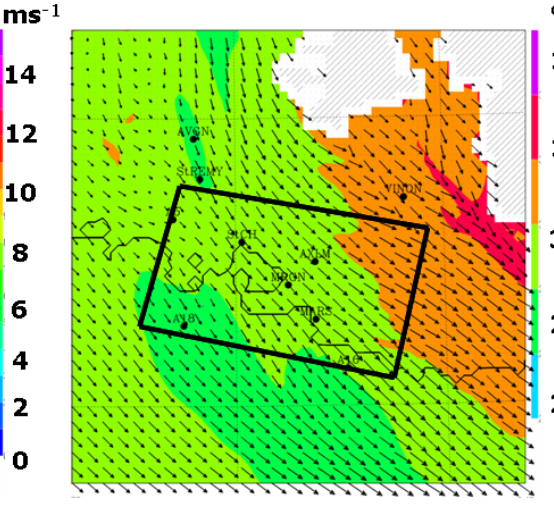

e) Potential temperature at $\mathbf{8 0 0 m}$

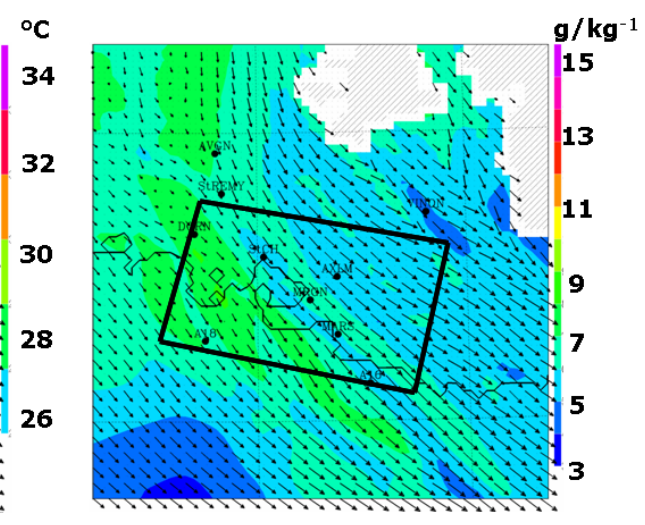

f) Water vapor mixing ratio at $800 \mathrm{~m}$

Fig. 3. Maps of wind speed and direction $\left(\mathrm{m} \mathrm{s}^{-1}\right)$, potential temperature $\left({ }^{\circ} \mathrm{C}\right)$ and water mixing ratio $\left(\mathrm{g} \mathrm{kg}^{-1}\right)$ at the surface (top) and at a 800-m height (bottom) simulated on 22 June at 12:00 UTC with Meso-NH. The quadrilatere delimits the area flown over by the aircraft.

to the maize transpiration and water deposition (for instance, the peak around 06:00 UTC is attributed to the morning dew). These results are in good agreement with those from Bastin et al. (2006), who investigated a wider domain than ours. They showed that the presence of the Mistral and other various mechanisms that drive its dynamics in different regions of the Rhône valley lead to a very inhomogeneous and unsteady behavior of the sea breeze at the scale of the Rhône valley exit. They observed that on $\mathrm{J} 22$, the sea breeze set up around 11:00 UTC at the west of the Rhône valley exit (at the south of the Massif Central) and then penetrated later inland, to the east of Marseille (14:00 UTC). They explained this by a strong sea-land temperature gradient on the western area where the ground could have warmed up due to the wind sheltering effect caused by the mountains of Massif Central.

Figure 3 presents the thermo-dynamical fields provided by the MesoNH simulation on J22, 12:00 UTC, at the surface and at the 800-m level (in the following section, we will show that the $800-\mathrm{m}$ level is within the ABL at 12:00 and 14:00 UTC for both days). Since no flight was operated on J22 at 14:00 UTC, we instead display the numerical fields at 12:00 UTC, so that we can compare them to the aircraft data which were recorded between 11:00 and 12:30 UTC. At the surface, the model simulates a south-westerly wind 


\section{Aircraft observations on June 22, 1200 UTC}

a) Horizontal wind speed $\left(\mathrm{ms}^{-1}\right)$ at $800 \mathrm{~m}$

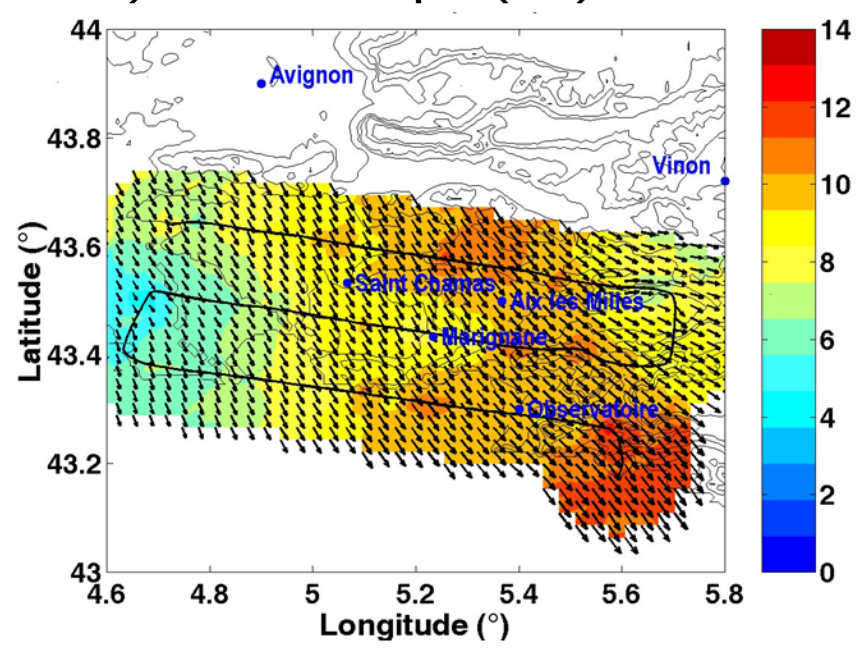

b) Potential temperature $\left({ }^{\circ} \mathrm{C}\right)$ at $800 \mathrm{~m}$

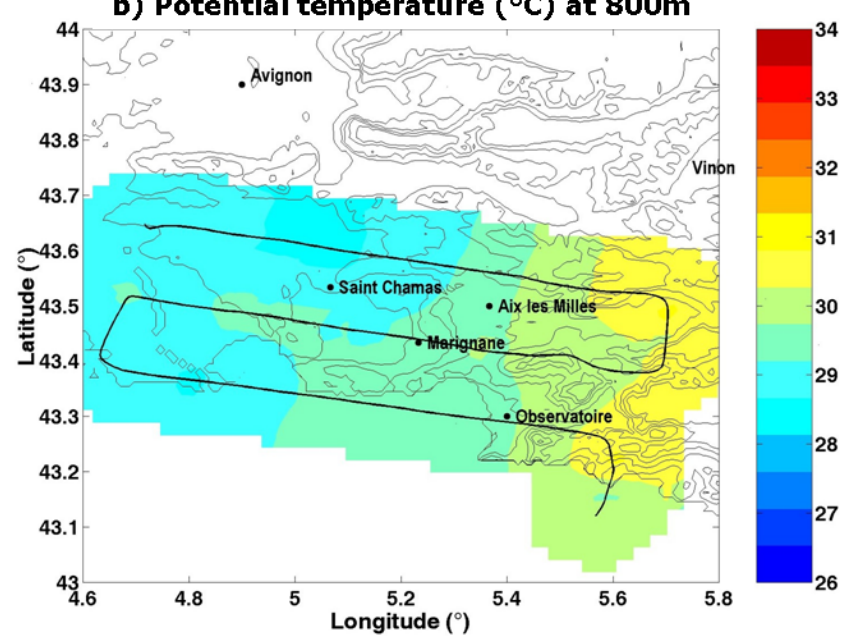

c) Water vapor mixing ratio $\left(\mathbf{g k g}^{-1}\right)$ at $800 \mathrm{~m}$

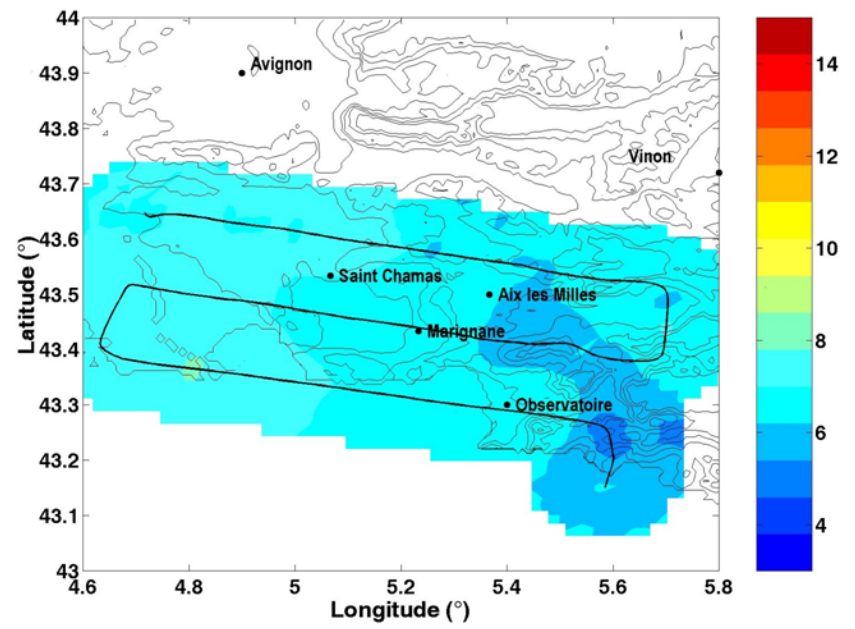

Fig. 4. Fields of wind speed (a), potential temperature (b) and water vapour mixing ratio (c) retrieved from aircraft measurements at $800 \mathrm{~m}$ on 22 June between 11:00 UTC and 12:30 UTC. The flight track is represented with a black solid line.

penetrating inland in the western part of the coast, to the west of the Berre Pond (Fig. 3a). The wind is from the west at the Marseille coastline. Inland, there is a very weak northerly flow in the Rhône valley which strengthens and turns northwest over the hills and mountains. In addition, the potential temperature field inland exhibits a west-east gradient that matches the relief (colder in the Rhône valley than over the mountains) (Fig. 3b).

At $800 \mathrm{~m}$, the dynamic and thermodynamic fields are quite different: the wind (Fig. 3d) is northerly to northwesterly with a magnitude of $6-7 \mathrm{~m} \mathrm{~s}^{-1}$ in the west, and up to $12 \mathrm{~m} \mathrm{~s}^{-1}$ in the east of the domain. The temperature field (Fig. 3e) displays a channel of a minimal value $\left(28^{\circ} \mathrm{C}\right)$ in the Rhône valley and maximum values in the east $\left(31-32^{\circ} \mathrm{C}\right)$ : the west-east gradient mentioned at the surface between the plain and the mountains is even more marked. At this level, the temperature gradient is due to the differential heating between the Rhône valley and the mountains (Alps to the east). This gradient vanishes over the sea and the flow corresponds to the Mistral exit out of the Rhône valley. So, the sea breeze does not affect the atmospheric layer at this altitude and this is confirmed with the humidity parameter (Fig. 3f): the field of water vapor mixing ratio is indeed rather homogeneous on the eastern region (both inland and over the sea), with a value of $6 \mathrm{~g} \mathrm{~kg}^{-1}$ and higher values $\left(7-8 \mathrm{~g} \mathrm{~kg}^{-1}\right)$ in the Rhône valley and downwind over the sea. The comparison of potential temperatures between both levels $\left(2^{\circ} \mathrm{C}\right.$ warmer at the ground than at $800 \mathrm{~m}$ over the Rhône valley; $3^{\circ} \mathrm{C}$ east of Vinon) suggests a strong instability in the ABL which is likely to yield high sensible heat fluxes inland.

The simulated fields at $800 \mathrm{~m}$ compare well to the aircraft data. On Fig. 4, the measured wind is blowing from 

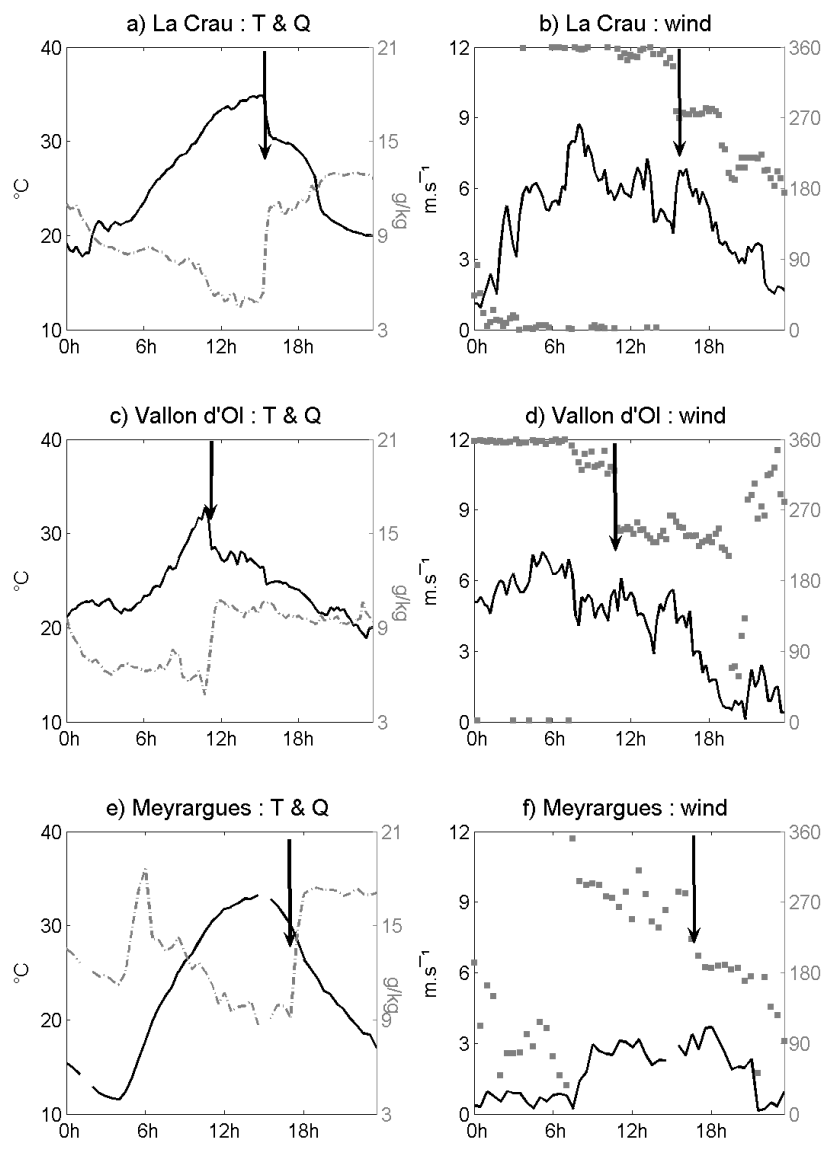

Fig. 5. Same as Fig. 2 for 23 June.

the northwest with a magnitude of $5-6 \mathrm{~m} \mathrm{~s}^{-1}$ at the exit of the Rhône valley and a magnitude of about $12 \mathrm{~m} \mathrm{~s}^{-1}$ in the central part of the mountains, showing good agreement with the numerical results. The potential temperature presents a west-east gradient, with temperatures increasing from $29^{\circ} \mathrm{C}$ to $31^{\circ} \mathrm{C}$, above the massifs of Sainte Baume and Sainte Victoire. Eventually, again in accordance with the numerical results, the humidity field is rather homogeneous, with the value of the water vapor mixing ratio varying around 6$7 \mathrm{~g} \mathrm{~kg}^{-1}$, slightly higher at the exit of the Rhône valley.

In the early afternoon (14:00 UTC, not shown here), the model can simulate the sea breeze at the surface but it is restricted to a short band along the coast between Saint Chamas and the east of Marseille. In fact, the onset occurs at 14:00 UTC in La Crau and 15:00 UTC in Vallon d'Ol (Table 1). As expected, the sea breeze is not observed in the numerical fields at $800 \mathrm{~m}$, at 14:00 UTC.

On $\mathbf{J} 23$, the meteorological situation is rather similar to J22. Figure 5 displays the time series of wind, temperature and humidity at the same ground sites on $\mathrm{J} 23$. The sea breeze clearly appears in La Crau around 15:30 UTC with a change in the wind direction from the north to the west, a sharp increase in the water vapor mixing ratio associated with a de- crease in potential temperature. The wind is veering again around 19:00 UTC, with a south-westerly direction. The air mass is even colder and moister. In the foothills of Marseille, the sea-breeze is detected at 11:00 UTC with an increase in the humidity rate associated with a decrease in temperature. The wind blows from the southwest until 20:00 UTC with no change in the humidity rate. The sea breeze reaches Meyrargues at 17:00 UTC: the wind starts veering from the northwest to the south, and the temperature decreases while the humidity increases. Although the sea breeze sets up earlier in Marseille on J23 compared to J22, it penetrates later in the Rhône valley and it even reaches the Durance valley entrance.

Since the sea-breeze onset occurred later inland than on the previous day, the 14:00 UTC situation is presented here. The Meso-NH simulations at 14:00 UTC do not show any sea-breeze penetration at the surface (Fig. 6), whereas it slightly penetrated inland on J22. The Mistral is well established in the Rhône valley channel with a speed of 6-7 $\mathrm{m} \mathrm{s}^{-1}$.

In Fig. 6b we can notice that the Mistral flow warms up as it blows above the warm ground of the Rhône valley exit. Therefore, this induces a large gradient of temperature and humidity when the Mistral air mass reaches the coast and meets the sea-breeze circulation, which conveys wetter and colder air. This gradient is associated with a west-east temperature (Fig. 6b) and humidity (Fig. 6c) gradient between the Rhône valley and the eastern mountains, even more marked than on the previous day.

At $800 \mathrm{~m}$, on $\mathbf{J} 23$, the numerical simulations show that the air mass from the Rhône valley is advected over the marine atmospheric surface layer. For instance, in Fig. 6d, the wind is orientated from the north to the northwest with an acceleration in a narrow band between Avignon and Marseille (11$12 \mathrm{~m} \mathrm{~s}^{-1}$ ), whereas its speed reaches 8 to $9 \mathrm{~m} \mathrm{~s}^{-1}$ at the borders of the domain. Compared to the aircraft measurements, a major difference appears in the wind field (Fig. 7a). Although the direction and the structure (i.e. the channelling effect along the axis "Saint Remy-Marseille") are correctly reproduced, the measurements provide lower values of the wind speed (between 5 to $9 \mathrm{~m} \mathrm{~s}^{-1}$ ) compared to those simulated $\left(6-13 \mathrm{~m} \mathrm{~s}^{-1}\right)$. At $800 \mathrm{~m}$, the temperature field obtained with the model (Fig. 6e) shows that the air mass has a minimum of potential temperature in the western part of the overflown area $\left(31^{\circ} \mathrm{C}\right)$ and a maximum in the eastern part $\left(34^{\circ} \mathrm{C}\right)$. This west-east gradient is clearly confirmed by the aircraft data field (Fig. 7b). On the humidity field (Fig. 6f), we find an east-west gradient (like the day before) with the mixing ratio of water vapour reaching $7 \mathrm{~g} \mathrm{~kg}^{-1}$ in the Rhône valley and $3-4 \mathrm{~g} \mathrm{~kg}^{-1}$ to the east. However, this gradient is not observed on the aircraft measurements (Fig. 7c), which do not show any organization but display humidity values in the same range $\left(3-7 \mathrm{~g} \mathrm{~kg}^{-1}\right)$. 


\section{Meso-NH simulations on June 23, 1400 UTC}

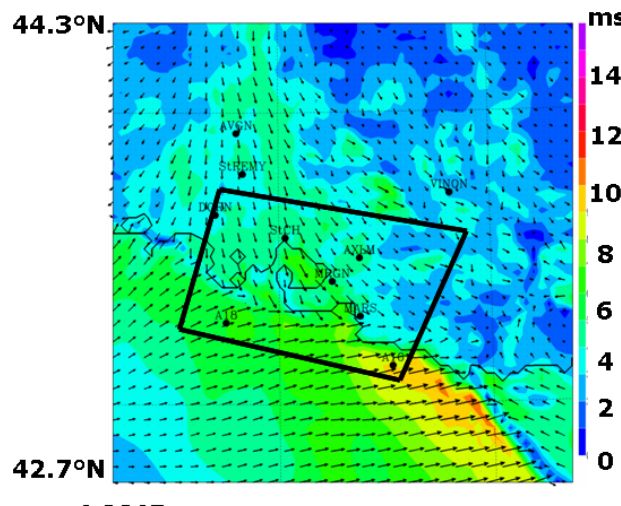

\section{$4.22^{\circ} \mathrm{E}$}

a) Wind field at the surface

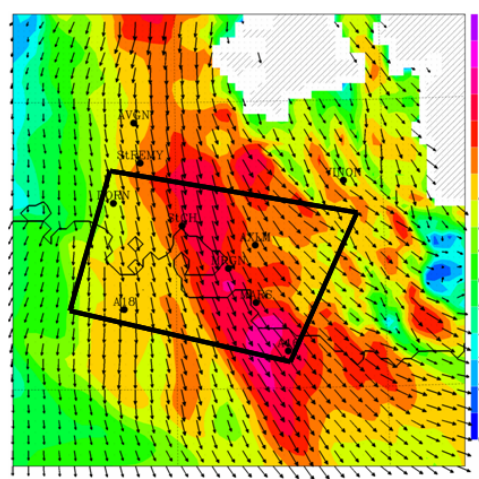

d) Wind field at $800 \mathrm{~m}$
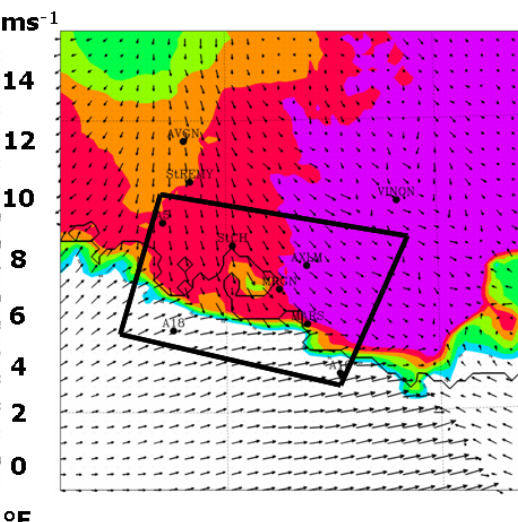
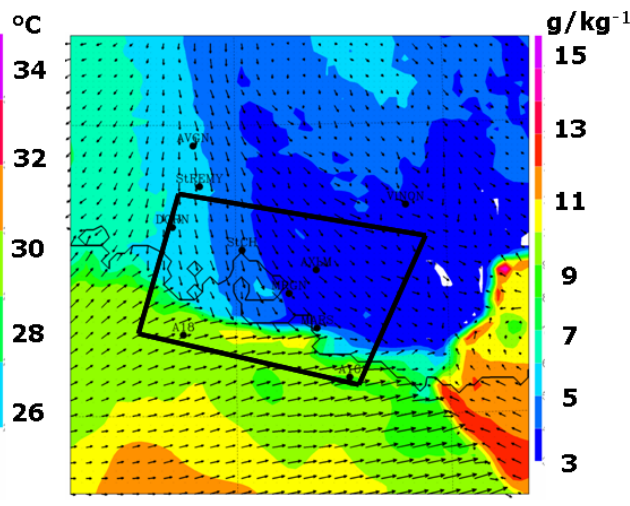

b) Potential temperature at the surface c) Water vapor mixing ratio at the surface

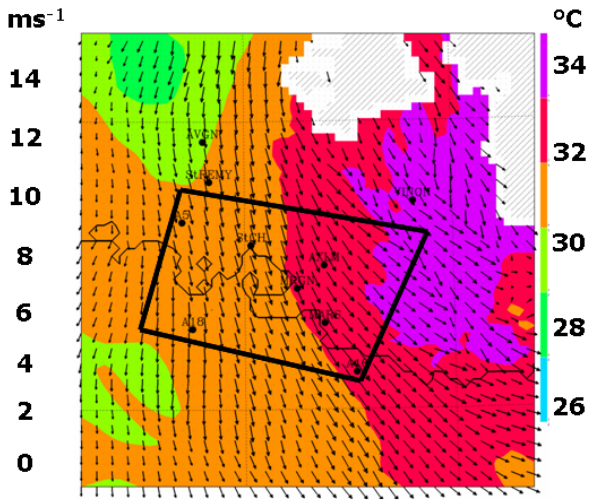

e) Potential temperature at $800 \mathrm{~m}$

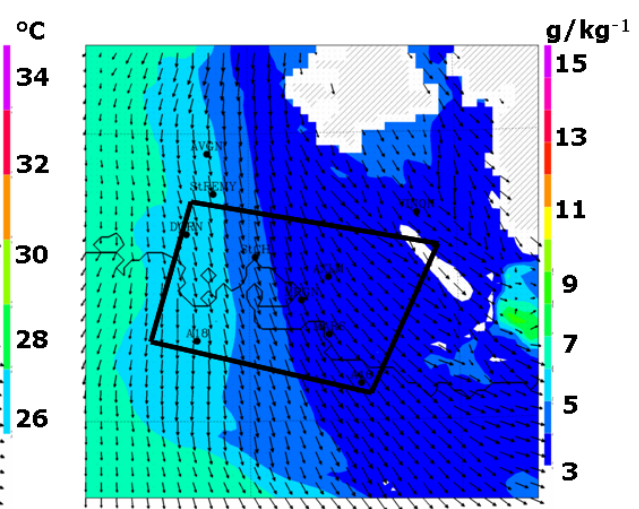

f) Water vapor mixing ratio at $\mathbf{8 0 0 m}$

Fig. 6. Same as Fig. 3 for 23 June, 14:00 UTC.

\subsection{The sea-breeze front along the coast during IOP2a}

To further analyze the differences in the sea-breeze onsets on J22 and J23, we investigated the sea-breeze vertical structure. Figure $8 \mathrm{~b}$ displays the height-time cross section of the horizontal wind measured with the UHF profiler in Saint Chamas. The sea-breeze westerly winds can be observed from 15:00 UTC on J22 in a layer up to $500 \mathrm{~m}$ and around 17:00 UTC on J23 in a thinner layer (up to $400 \mathrm{~m}$ ). So the sea-breeze appears at around the same time in Saint Chamas (15:00 UTC), La Crau (14:00 UTC) and Vallon D'ol (14:30 UTC) on J22, whereas the onset times are 17:00, 15:30 and 11:00 on J23. Figure 9 shows a height-latitude south-north cross section of the simulated horizontal wind along an axis Marseille-Aix en Provence on J22 (a) and J23 (b) at 15:00 UTC (the horizontal track of the cross section is shown in Fig. 16). The colored scale represents the potential temperature. On 22 June, the sea-breeze appears as a westerly wind layer, with a stratified potential temperature structure (blue color) which extends up to $200 \mathrm{~m}$ in altitude and to the northern foothills of Marseille in latitude. It does not penetrate far inland and does not reach Aix en Provence. The atmosphere is stratified over this marine layer and the wind is a composition between the Mistral (blowing from the north-west at $1000 \mathrm{~m}$ ) and the westerly sea-breeze flow. Over the continent, a mixed boundary layer is developed in the Mistral flow from $1200 \mathrm{~m}$ (north to Marseille) to $1800 \mathrm{~m}$, at the northernest point of the section.

On 23 June (Fig. 9b), the simulation shows that the sea breeze has hardly penetrated in Marseille, although it has been detected since 11:00 UTC with in-situ measurements (at Vallon d'Ol). It remains confined in the very lowest levels of the atmosphere. This effect is enhanced in the simulation since the Mistral magnitude is overestimated by Meso-NH, as noted in the previous section. The stratified layer capping the sea breeze layer is disorganized by the continental layer that is advected over the sea by the mistral flow.

Thus, for these two days, the sea breeze occurs during the afternoon (except in Marseille on J23), roughly at the same time at the scale of the studied area. No real sea-breeze layer develops because the sea breeze is not strong enough to struggle with the Mistral. However, the marine surface layer that penetrates over the continent disconnects the boundary layer from the surface. The Mistral is also advected offshore, over the sea-breeze layer, on J23. 


\section{Aircraft observations on June 23, 1400 UTC}

a) Horizontal wind speed $\left(\mathrm{ms}^{-1}\right)$ at $800 \mathrm{~m}$

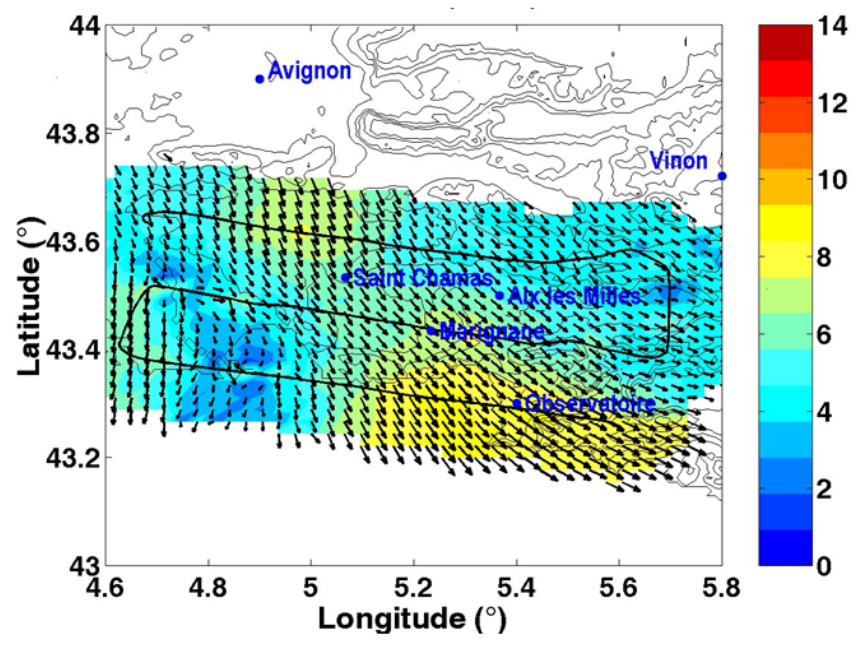

b) Potential temperature $\left({ }^{\circ} \mathrm{C}\right)$ at $800 \mathrm{~m}$

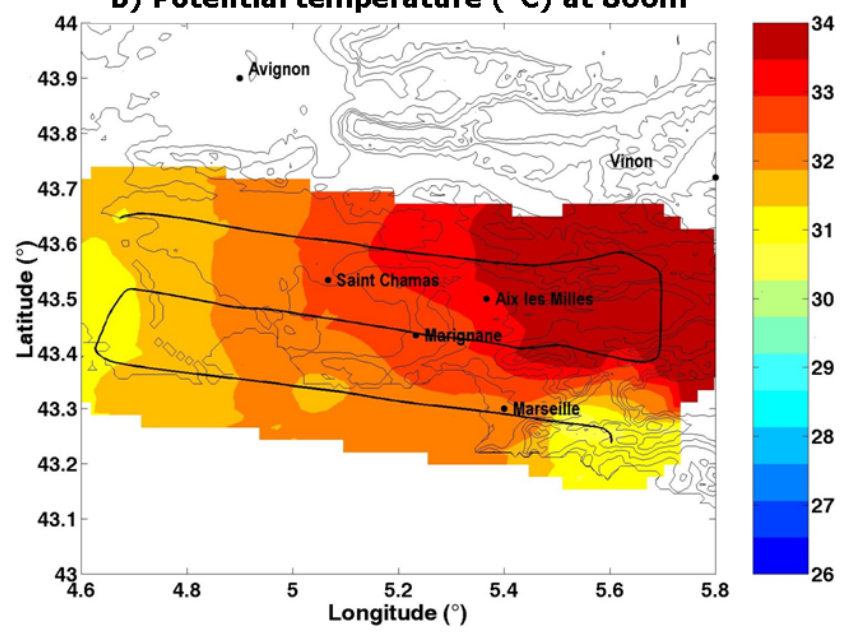

c) Water vapor mixing ratio $\left(\mathbf{g k g}^{-1}\right)$ at $\mathbf{8 0 0 m}$

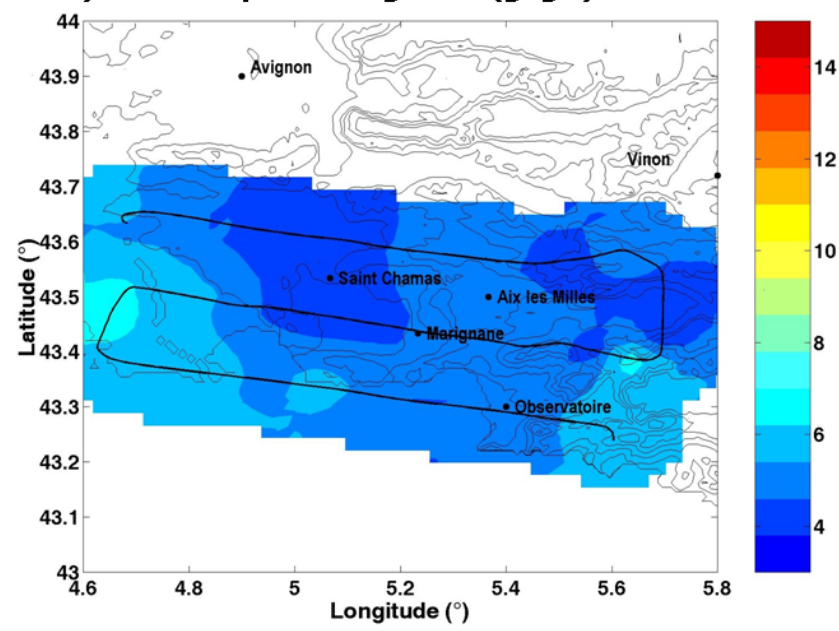

Fig. 7. Same as Fig. 4 for 23 June, 14:00 UTC.

4.3 Validation of the model on a pure sea-breeze case: 25 June 2001

The meteorological situation changed during IOP2b and turned to well-marked sea-breeze conditions. As indicated in Table 1, the sea breeze beginning is detected earlier on J24 than on the previous days (around 09:00, 07:00 and 12:00 UTC at La Crau, Vallon D'Ol and Meyrargues, respectively). On J25, which is a pure sea-breeze event, and J26, which corresponds to a synoptic situation from the south, the sea breeze starts early in Vallon d'Ol and La Crau and reaches Meyrargues more or less later in the morning. Figure 10 displays the meteorological parameters measured at the ground-based stations in La Crau, Vallon d'Ol and Meyrargues on J25. The temperature cycles in Meyrargues and La Crau are bell-shaped, contrary to the rather flat one observed in Marseille. Actually, we can observe this flat type of cycle during the whole IOP2b: the sea breeze in Marseille prevents the potential temperature from increasing. On the Meso-NH temperature fields at the surface (Fig. 11b), we can note that the temperature gradient is very strong and homogeneous along the coast. Therefore, the advection of colder maritime air penetrates further inland compared to IOP2a. The field is homogeneous inland with values around $34^{\circ} \mathrm{C}$ at 14:00 UTC.

The sea-breeze direction is from the west (i.e. perpendicular to the coast) in Marseille and from the south in La Crau and southwest in Meyrargues. The simulations at 12:00 UTC and 14:00 UTC show similar results as the measurements. The ground measurements of Vallon D'ol are representative of the sea-breeze flow in the eastern part of the domain (south-west direction) but are slightly different from the observations and model results (westerly flow) downtown in Marseille, due to the direction of the coastline (Delbarre et al., 2005). 

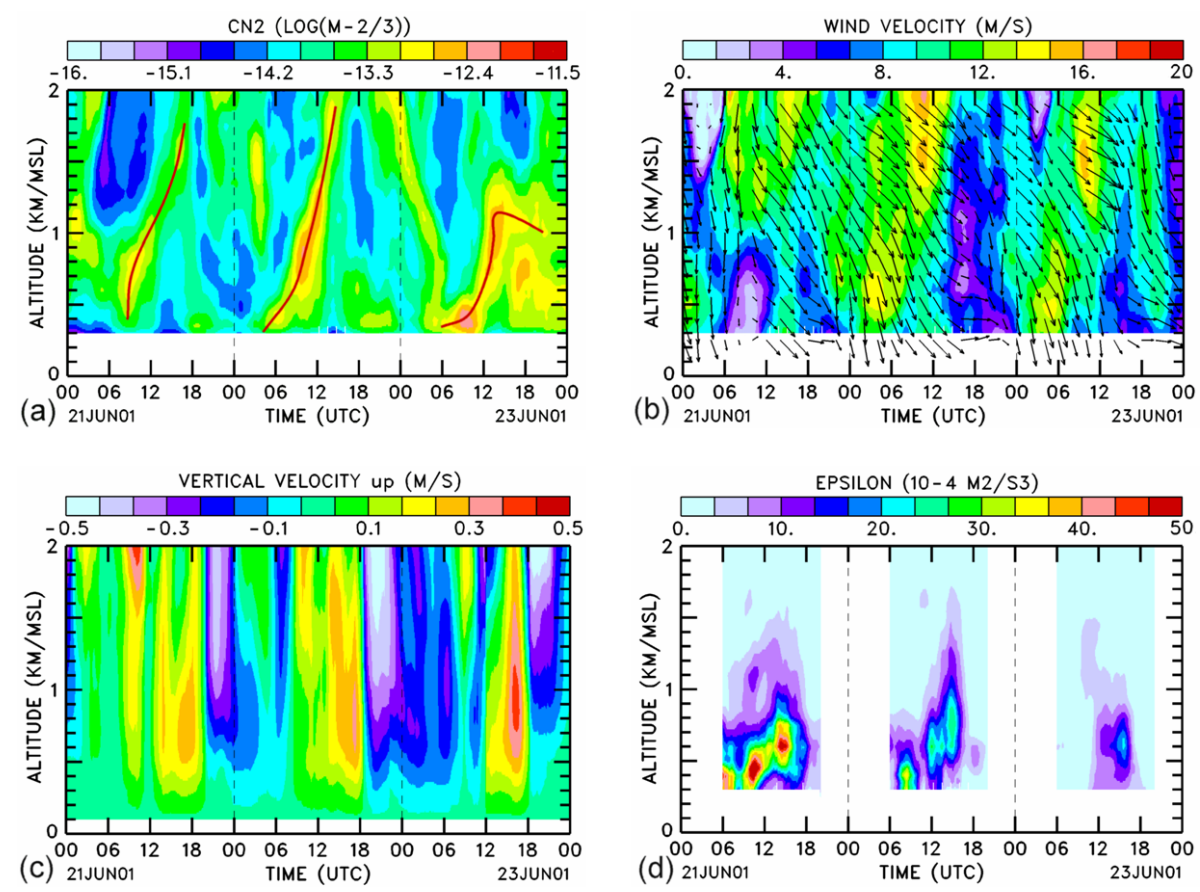

Fig. 8. Height-time cross sections of the structure constant $\mathrm{Cn}^{2}\left(\mathrm{~m}^{-2 / 3}\right)(\mathbf{a})$, horizontal wind $\left(\mathrm{m} \mathrm{s}^{-1}\right)(\mathbf{b})$, vertical velocity (m s $\left.\mathrm{s}^{-1}\right)(\mathbf{c})$ and dissipation rate of turbulent kinetic energy $\left(10^{-4} \mathrm{~m}^{2} \mathrm{~s}^{-3}\right)$ measured with the UHF wind profiler in Saint Chamas during the Mistral episode (J21 to J23). The red solid line in panel (a) represents the ABL top height.

In general, due to the weak values of the wind speed ( 2 to $5 \mathrm{~m} \mathrm{~s}^{-1}$ ), there is a strong spatial variability in the wind direction on J25. At 14:00 UTC, the wind is very weak in the northern part of the domain (Fig. 11a-d) that is not reached by the sea breeze yet. In the eastern part, a well marked south flow generates a convergence area over the eastern relief. In the southwest part of the area the sea breeze can reach 5 to $7 \mathrm{~m} \mathrm{~s}^{-1}$.

Contrary to the situation of IOP2a, we do not observe a strong increase in the humidity rate with the sea-breeze onset, especially in La Crau plain (Fig. 10a). In Meyrargues, because of the transpiration of the maize, the water vapour mixing ratio is higher than at the other sites. These data compare well with the numerical fields of temperature and humidity at the surface (Fig. 11b-c). On the modelling results, we find again a strong humidity gradient along the coast but there is no noticeable advection of moist air due to the sea breeze. The mountainous areas in the east seem to be moister than in the region north of the Berre pond (between Saint Chamas and Aix en Provence). At the 800-m level, the humidity rate is higher over the continent, which is not surprising considering that the air masses are completely disconnected: as we will see in the next section, $800 \mathrm{~m}$ is either inside or over the internal boundary layer generated by the sea breeze.

It is more difficult to correctly simulate the wind field during IOP2b, because the wind has weakened and become unsteady. The sea breeze sets up earlier than during IOP2a but local winds are dominating and the vertical structure of the low troposphere is very heterogeneous, even inside the seabreeze layer.

In the next section, we will show that the decoupling between the surface and the $800-\mathrm{m}$ level is essentially due to the various stages of sea-breeze penetration.

\section{ABL development}

\subsection{ABL height: definition and estimation}

This section is devoted to the description and the analysis of the ABL development over the ESCOMPTE area during IOP2a and IOP2b. The depth of the ABL is a crucial parameter since it drives the volume of air within which the pollutants are likely to be either diluted or concentrated. It is indeed a hard task to define a ABL height in Marseille's surroundings where you can find together a big city, a complex coastline and hilly terrains. Delbarre et al. (2005) highlighted the complexity of the air circulation in this area under sea-breeze conditions. By studying the extinction of a UV lidar signal along with the turbulence and reflectivity measurements of a UHF radar and radiosounding data, they showed, on J26, the existence of a 300-m deep layer with a westerly sea breeze, capped by a southerly flow extending to $800 \mathrm{~m}$ or $1000 \mathrm{~m}$ above the ground level. Those two 

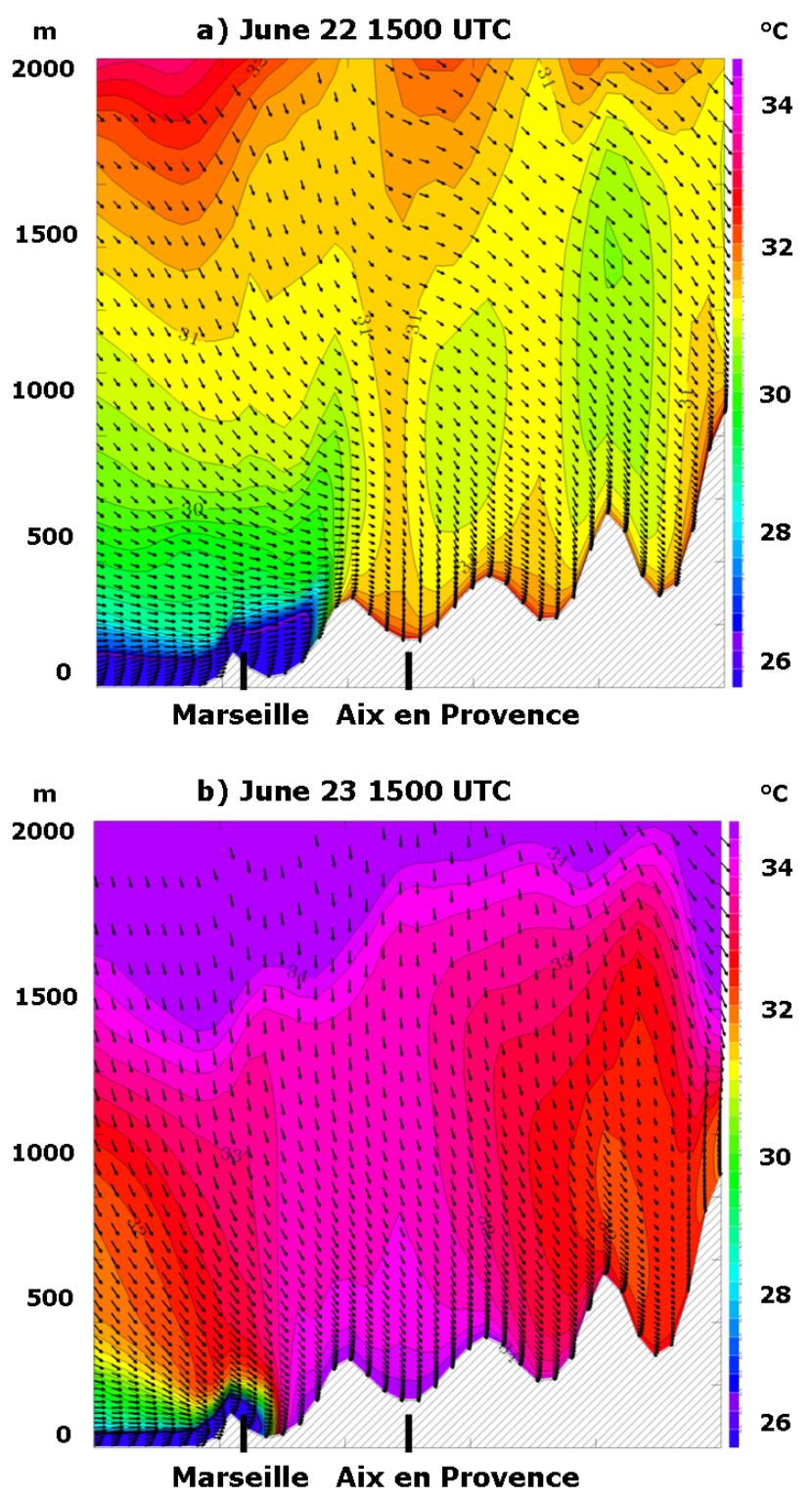

Fig. 9. Vertical section of potential temperature (color scale) and horizontal wind simulated by Meso-NH along an axis MarseilleAix en Provence on 22 June at 15:00 UTC (a) and on 23 June at 15:00 UTC (b). The location of the cross section is shown in Fig. 16b.

layers were characterized by different turbulence properties and were separated by thin stable layers, inhibiting the exchanges. Lemonsu et al. (2006) also highlighted this superposition of two sea breezes, using a large eddy simulation with a 250-m resolution in the vicinity of Marseille.

Therefore, the difficulty of the present work was to find a means of defining an ABL in such complex situations, or at least a level likely to indicate a disconnection between an area of local exchanges (exchanges between the various internal layers) and the free atmosphere. Since we did not
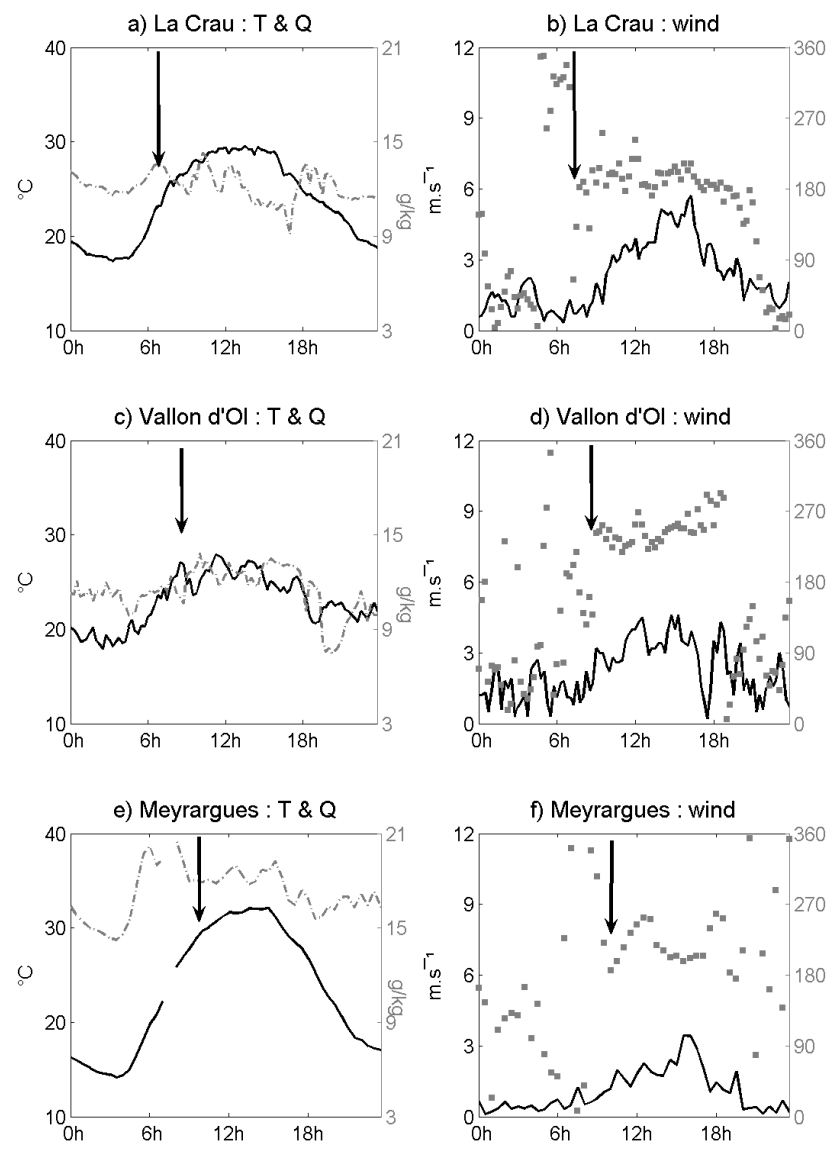

Fig. 10. Same as Fig. 2 for 25 June.

observe conditions of a classical mixed layer for this definition (which would mean a constant potential temperature and constant scalars concentration), we define $Z_{i}$ (which usually corresponds to the ABL top) as the capping level of all the turbulent superimposed layers. This level corresponds to a sharp inversion that clearly indicates the separation with the stable layers of the free troposphere. This multi-layer ABL topped by level $Z_{i}$ can be considered as a reservoir whose chemical species may exchange from one layer to another.

For the whole IOP2, the ABL height $Z_{i}$ was determined using both numerical and experimental results. We used profiles of potential temperature and humidity from radioballoon- and aircraft-soundings (Fig. 12), as well as timeheight cross sections of reflectivity provided by the UHF radars (Fig. 8a). In addition to the available measured data, $Z_{i}$ was estimated using the vertical sections of potential temperature provided by the Meso-NH simulations. From these vertical sections, the ABL height is obtained from the maximum of the temperature gradient which usually follows the "ridge" of the isothermal lines along the section. However, it remained difficult to define standard criteria to determine the ABL depth in an area where it varies very sharply. 


\section{Meso-NH simulations on June 25, 1400 UTC}

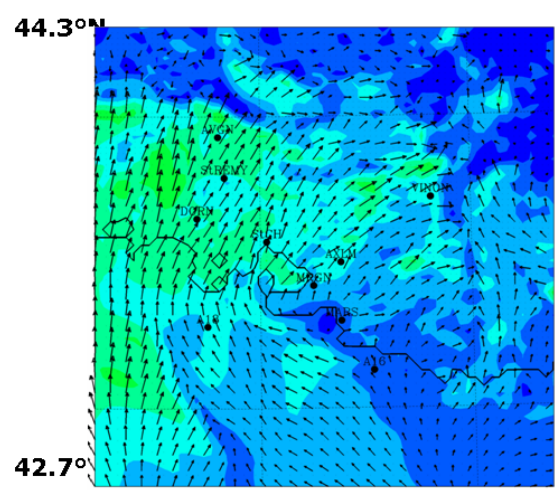

4.22 ${ }^{\circ} \mathrm{E}$

a) Wind field at the surface

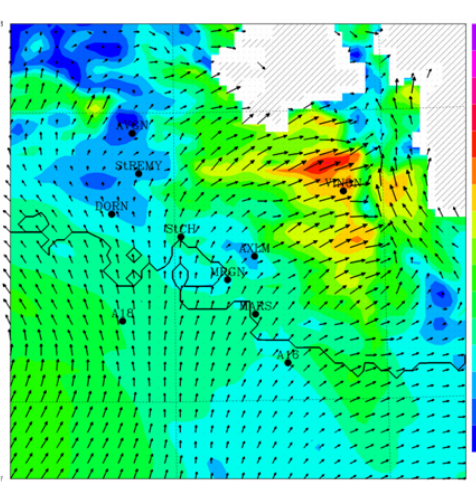

d) Wind field at $800 \mathrm{~m}$

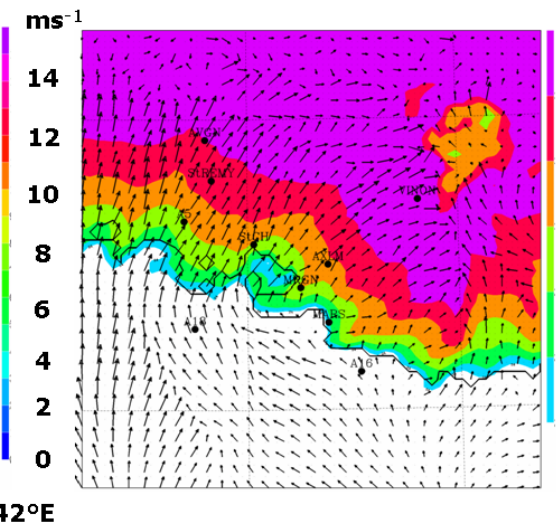

b) Potential temperature at the surface c) Water vapor mixing ratio at the surface

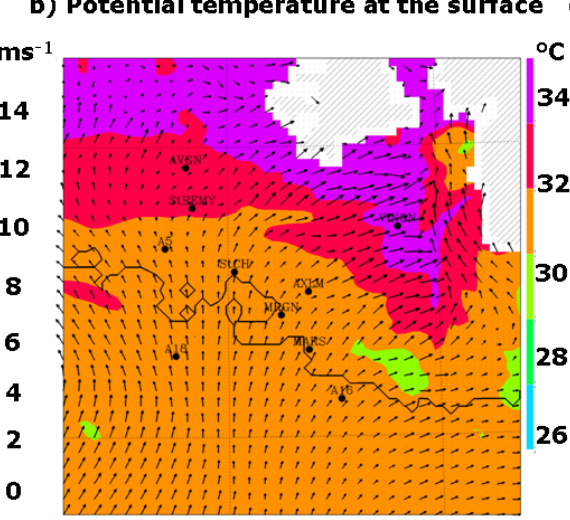

e) Potential temperature at $\mathbf{8 0 0 m}$
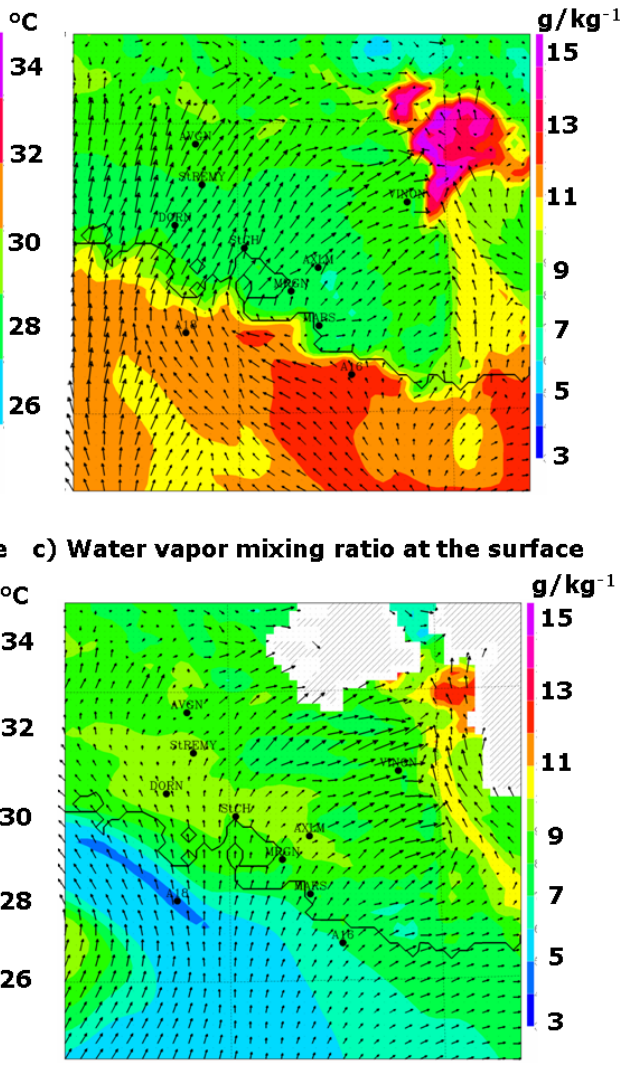

f) Water vapor mixing ratio at $800 \mathrm{~m}$

Fig. 11. Same as Fig. 3 for 25 June, 14:00 UTC.

Nevertheless, to retrieve maps of the ABL depth from modeling results, we used zonal and meridian vertical sections of the potential temperature every 0.1 degree in longitude and latitude, respectively. The values of $Z_{i}-Z_{r}$ (where $Z_{r}$ is the ground surface height) were linearly interpolated over the ESCOMPTE domain, in order to provide maps of the ABL depths at 11:00 and 14:00 UTC for IOP2a and IOP2b. These fields are shown, respectively, in Figs. 13 and 14. This representation in terms of depth of the ABL instead of height has been preferred to outline the effect of the complex terrain in the following. The experimental results are also reported on these maps.

\subsection{Comparison between model and experimental results}

The simulated ABL depth fields were validated using the experimental data, at 11:00 and 14:00 UTC, which coincides to the times at mid-flight. The comparison is shown as bar diagrams in Fig. 15 and the difference is reported in Table 2, in terms of a mean relative difference between simulated and experimental data. A distinction is made between the results in the plain and near the coast and the results obtained in Vinon, in a mountainous surrounding. The bar diagrams are
Table 2. Mean relative error between simulated $Z_{i}$ and measured $Z_{i}$ using the experimental data collected at St Rémy, Arles, St Chamas, Marignane and Aix-Les-Milles (without Vinon) and in the mountain area (Vinon).

\begin{tabular}{llllll}
\hline$\Delta \mathrm{Z}_{i}(\exp -\operatorname{sim}) / \mathrm{Z}_{i} \exp$ & $22 / 06$ & $23 / 06$ & $24 / 06$ & $25 / 06$ & $26 / 06$ \\
\hline $\begin{array}{l}\text { 11:00 UTC } \\
\text { (without Vinon) }\end{array}$ & 0.12 & 0.03 & 0.22 & 0.27 & 0.11 \\
$\begin{array}{l}\text { 11:00 UTC } \\
\text { (at Vinon) }\end{array}$ & 0.10 & 0.00 & 0.91 & 0.33 & 0.00 \\
$\begin{array}{l}\text { 14:00 UTC } \\
\text { (without Vinon) }\end{array}$ & 0.22 & 0.09 & 0.08 & 0.05 & 0.00 \\
$\begin{array}{l}\text { 14:00 UTC } \\
\text { (at Vinon) }\end{array}$ & 0.12 & 0.40 & 0.45 & 0.43 & 0.08 \\
\hline
\end{tabular}

presented for seven locations, which are indicated according to their name, their longitude or their shortest distance to the sea.

At 11:00 UTC or 14:00 UTC, the difference between model and experience does not exceed $20 \%$ for $60 \%$ of the results (Table 2). The ABL height is usually well estimated 

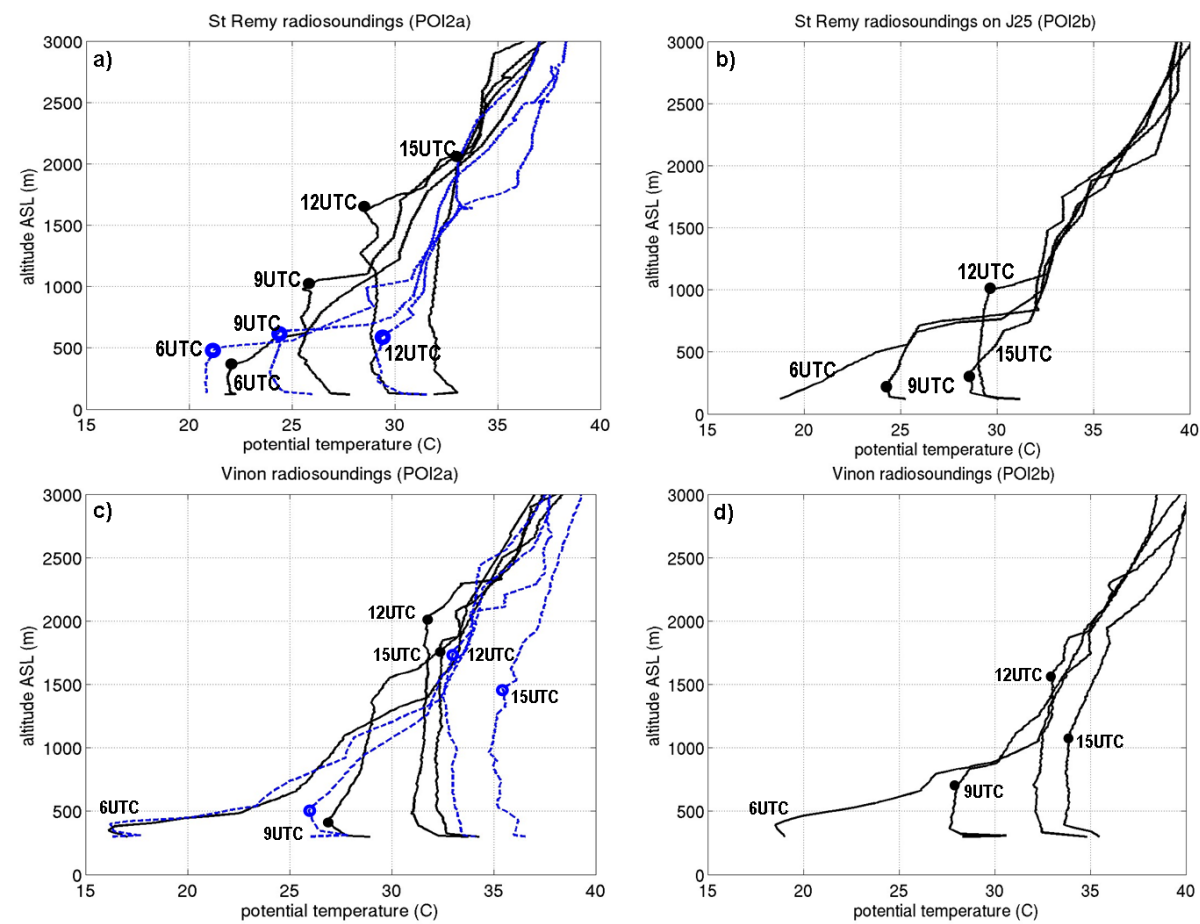

Fig. 12. Potential temperature profiles from radio-soundings launched at Saint Rémy (top) and Vinon (bottom) during IOP 2 a (left): J22 (solid black line) and J23 (dashed blue line) and on J25 for IOP 2b (right) at 06:00, 09:00, 12:00 and 15:00 UTC.

inland over the plain (Avignon, Arles, St Rémy) (left part of the bar diagrams in Fig. 15), whereas the largest errors are often due to an underestimation of the ABL near the coast at 11:00 UTC (central part of the bar diagrams). This is not surprising during IOP2b, since the sea breeze is in a transition phase at this hour of the day. At 11:00 UTC the simulated sea-breeze front may not be exactly positioned at the right location, since the simulated onset time is sometimes delayed in comparison to the observations (Table 1: Vallon d'Ol on J24 and J26, for instance). This argument is confirmed by the results at 14:00 UTC which show a real improvement in the ABL estimation near the coast. Actually, the error range, which also includes some of the inland sites, such as St Rémy, Arles or Avignon, decreased from 3-27\% to $0-9 \%$ from 11:00 UTC to 14:00 UTC. However, it must be noted that the ABL estimates at 14:00 UTC for J22 are removed from these results, as they present large discrepancies due to the Marseille case. This will be discussed below.

The case of Vinon is shown apart due to the specific behaviour of the ABL over the mountain. Both model and experience display an obvious west-east positive gradient in $Z_{i}$, (see, for instance, Fig. 15 at 11:00 UTC). This is not surprising, owing to the increase of the relief between the Rhône valley and the eastern mountain. We will see in the following that this increase in the $Z_{i}$ (ASL) level is not only due to the relief but also to the deepening of the ABL over the mountain. However, the model tends to overestimate this increase at 11:00 UTC as at 14:00 UTC, especially on J24 and
J25, with an error often reaching $40 \%$ (and even $91 \%$ once) (Table 2). This situation is due to some specific features of the simulated wind fields for these days: they exhibit a convergence area on the eastern mountains between the westerly (J24) or south-westerly (J25) sea-breeze flow and a south or south-east flow, to the east of the domain. The observations do not confirm this convergence area. On J24, the observed field exhibits a west-east gradient consistent with the upslope wind generated by the temperature gradient between the Rhône valley and the mountains. This is favourable for an increase in the ABL over the relief, but this increase is not as strong as the one induced by the simulated convergence.

To further validate the spatial variability of the ABL height retrieved from the simulations, we also used fields of turbulent kinetic energy (TKE) dissipation rate, estimated from aircraft data at the height of $800 \mathrm{~m}$. This parameter does not provide the $\mathrm{ABL}$ depth but it is a means to discriminate whether the $800-\mathrm{m}$ level (flight level) is inside or outside the $\mathrm{ABL}$. This was very useful near the seashore where very few vertical sounding were performed and where the ABL was often very low due to the sea breeze. An example of the field of the TKE dissipation rate obtained with the aircraft on J25 around 11:00 UTC is shown in Fig. 16a. It clearly shows that the ABL is higher above the mountainous area, to the east to St Chamas and over a narrow strip in the west corresponding to the Alpilles ridge. To aid the comparison with the $Z_{i}$-height retrieved with the model (Fig. 16b), we added on the latter the line corresponding to $Z_{i}=800 \mathrm{~m}$. There again, 
the Alpilles ridge is shown to be entirely inside the $\mathrm{ABL}$ at $800 \mathrm{~m}$, whereas Avignon or the coastal area south of the Alpilles are outside the ABL at this level. Aix-les-Milles is just at the border, both for the model and the experiment.

So, we can conclude that the model results and measurements are in good agreement on the whole and when discrepancies occur, this can be attributed to either a phase delay between the simulations and the measurements or to a wrong simulation of the flow around the mountains under weak wind conditions. This conclusion allows us to use the numerical results for our further comments on the ABL development.

5.3 Spatial and temporal variability of the ABL development

The previous comparison began to highlight different ABL heights according to the location relative to the coast or to the relief, according to the meteorological situation (IOP2a or IOP2b) and finally, according to the time of day and the various diurnal evolutions of the ABL. The following study relies upon the radiosoundings in Fig. 12 (ABL heights) and the maps of $Z_{i}-Z_{r}$ (ABL depths) presented in Figs. 13 and 14 for both IOPs. Several striking features can be pointed out:

\subsubsection{IOP2a - different ABL behaviors over the plain for the two days}

Although the meteorological conditions are very similar on J22 and J23, the ABL developed differently over the plain. The ABL depth hardly reaches $600 \mathrm{~m}$ in the westerly part of the domain on J23 (Fig. 13), whereas it could reach $1500 \mathrm{~m}$ at the same hour in Arles the previous day. The first day of IOP2a shows a typical development of a convective ABL under summer clear conditions. In Saint Rémy, $Z_{i}$ increases from $350 \mathrm{~m}$ at 06:00 UTC to $1600 \mathrm{~m}$ at 12:00 UTC (Fig. 12). In Fig. 8, which shows the sketch of radar parameters measured at Saint Chamas (but it is nearly the same in the other radar locations) for three successive Mistral days, the striking feature is the repetitiveness of some cycles in the horizontal wind organization, in the ABL height (at least for the first two days) and in the vertical velocity during the three days. For instance, the ABL development can be followed using the time-height cross section of reflectivity (Fig. 8a). In this figure, the top of the ABL is deduced from the maximum of the reflectivity signal that reflects the sharp humidity gradient at the inversion level. It clearly appears that the ABL increases faster and higher in Saint Chamas on 22 June than on 23 June. The rapid and deep development of $Z_{i}$ on J21 and $\mathrm{J} 22$ is due to strong, sensible heat fluxes (in Marseille, we observe a maximum value of $450 \mathrm{Wm}^{-2}$ on $\mathrm{J} 22$ ), resulting from the high difference in temperature and the specific humidity between the surface and the colder and drier air masses transported by the Mistral wind. TKE is strong as well, as seen in Fig. 8d. On J23, the ABL height shown in Fig. 12, or its depth presented on the left part of Fig. 13, remains very low over the plain, although the Mistral conditions persist with strong northerly winds (Fig. 8b) (the maximum value of the sensible heat flux in Marseille is $300 \mathrm{Wm}^{-2}$ on J23). According to Gheusi et al. (2004), the sea breeze has set up very early further to the west of the ESCOMPTE domain on J23 in an area where the Mistral wind has weakened due to the sheltering effect of the Massif Central. Nevertheless, this is not the case in our studied area, except very close to the surface, as was previously shown with the ground stations (Table 1). Even close to the coast, as in Marseille, the sea-breeze vertical extent, which could prevent the ABL from developing, does not reach $500 \mathrm{~m}$ before 15:00 UTC (westerly direction in Fig. 8b). However, in spite of persistent Mistral conditions in St Rémy, the ABL depth remains constant between 09:00 UTC and 12:00 UTC (Fig. 12). In fact, a strong inversion at 09:00 UTC inhibits the development of the ABL. This strong inversion is linked to both a warming of the upper layers (Mistral weakening in altitude) and a cooling of the surface conditions (Fig. 12: $29^{\circ} \mathrm{C}$ at $1500 \mathrm{~m}, 12: 00 \mathrm{UTC}$ on $\mathrm{J} 22$ for $33^{\circ} \mathrm{C}$ on $\mathrm{J} 23 ; 22^{\circ} \mathrm{C}$ below $300 \mathrm{~m}$, 06:00 UTC on $\mathrm{J} 22$ for $21^{\circ} \mathrm{C}$ on $\mathrm{J} 23$ ). In addition, a strong negative vertical velocity affecting the first $2 \mathrm{~km}$ of the low troposphere is maintained all morning long on $\mathrm{J} 23$ (Fig. 8d), whereas it disappears after 08:00 UTC for J22.

$$
\begin{aligned}
& \text { 5.3.2 IOP2a - high spatial variability of the ABL for both } \\
& \text { days }
\end{aligned}
$$

If we now focus on the spatial variability of the ABL developments for these two days, we can notice that the development is quite homogeneous on $\mathbf{J} 22$, with $\mathrm{ABL}$ depths ranging between 1000 and $1500 \mathrm{~m}$ and a variation that can be linked to the wind velocity distribution (Fig. 4): the ABL is the lowest when the wind is the strongest $\left(12 \mathrm{~m} \mathrm{~s}^{-1}\right)$, showing that dynamics prevails over thermodynamics.

The north-south oriented part of the Durance valley (including Vinon) clearly displays some higher ABL, which are favored by the constriction of the flow in the valley that accelerates the wind and generates turbulence (Bastin et al., 2005a). Another source of prevalent development is the mechanism of valley breeze, which can be clearly seen on the Vinon ABL heights shown in Fig. $12 \mathrm{c} . Z_{i}$ is very low at 09:00 UTC, due to the down-slope wind that brings cold air to the valley bottom, inhibiting the ABL development. Between 09:00 UTC and 12:00 UTC, the differential heating between the slopes and valley bottom, reverses the surface flow and the ABL can grow rapidly, then it decreases again in the early afternoon associated with the up-slope wind weakening. This is supported by the surface wind in Meyrargues, at the Durance valley entrance, which turns from the east to the west on J22 between 06:00 and 09:00 UTC (Fig. 2f). It starts decreasing from 14:00 UTC. 

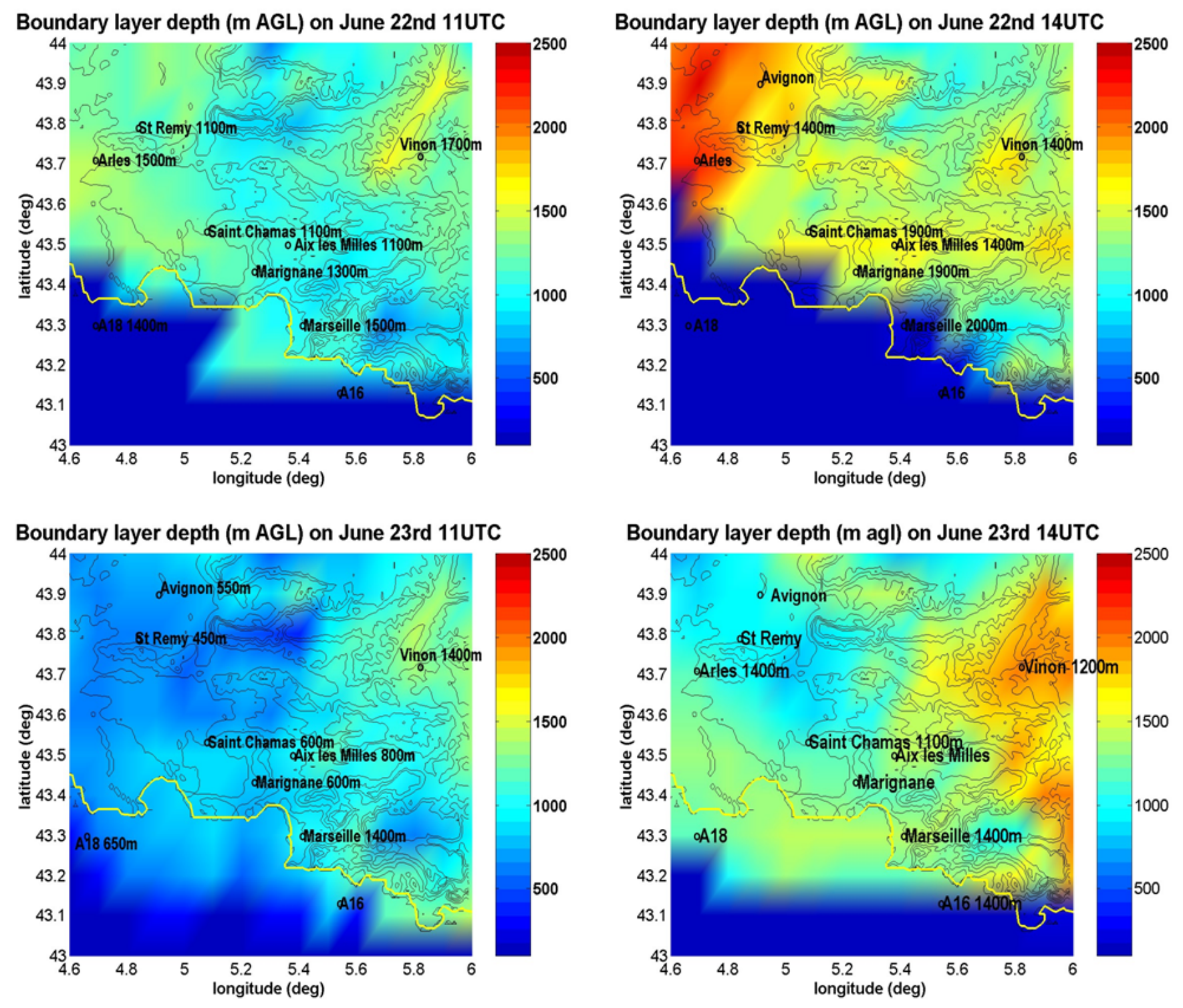

Fig. 13. Horizontal fields of atmospheric boundary layer depth obtained from the Meso NH simulations (colored scale) or experimental data (black labels), during IOP2a at 11:00 UTC (left) and 14:00 UTC (right).

Due to the low development of the ABL over the plain on $\mathrm{J} 23$ at 11:00 UTC, the difference in the ABL depths between the plain $(500-600 \mathrm{~m})$ and the mountain $(1000$ to $1400 \mathrm{~m})$ is even more marked. The ABL in the Durance valley, near Vinon, remains higher than in the surroundings.

Another huge difference appears between both days, when looking at the 14:00 UTC maps (right part of Fig. 13): the ABL has highly deepened during the 3-h lapse time, reaching $2000 \mathrm{~m}$ in some areas. It preferentially develops over the plain on $\mathrm{J} 22$, and over the mountain on $\mathrm{J} 23$. On $\mathrm{J} 22$, it is due to the important heating of the air over the plain: the ABL depth has reached the temperature of the free troposphere, so that it can develop more easily (no inversion). On J23, the ABL has hardly been able to break the inversion between 11:00 and 14:00 UTC over the plain, so it cannot increase as much as the day before.

Another source of wind circulation may occur at mesoscale, due to the difference in radiative heating between the Rhône valley and the Alps foothill: $1.5^{\circ} \mathrm{C}$ on J22, 11:00 UTC (Fig. $4 b$ ); $4.5^{\circ} \mathrm{C}$ on J23 at 11:00 UTC and $5^{\circ} \mathrm{C}$ at 14:00 UTC (Fig. 7b). This temperature gradient previously underlined between both areas may generate an upslope wind, roughly west-east, which could favor the ABL development over the relief. This mesoscale flow is, however, inhibited when the synoptic flow is strong, as it has been observed on J22: in this case, the ABL is not as deep 


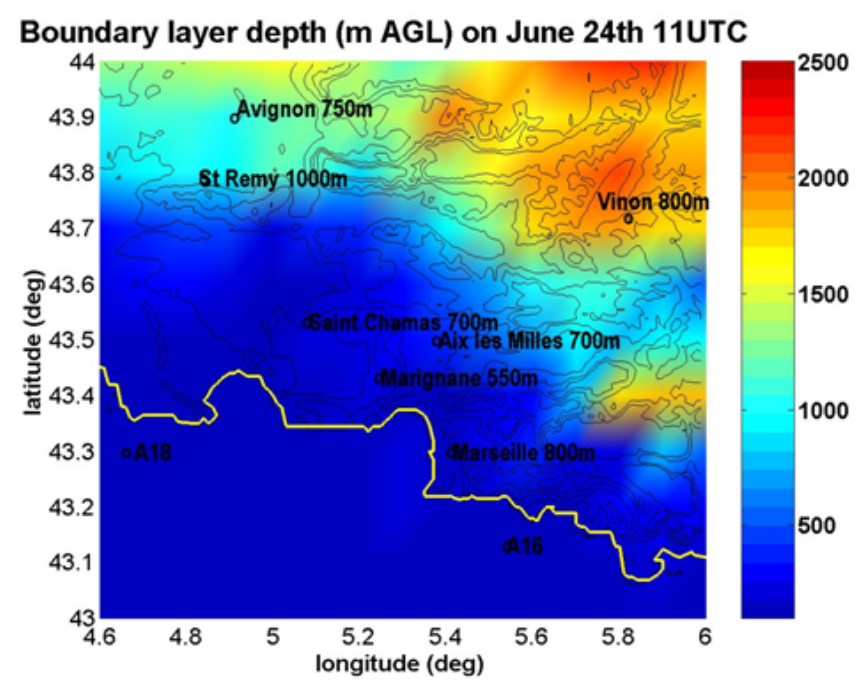

Boundary layer depth (m AGL) on June 25th 11UTC

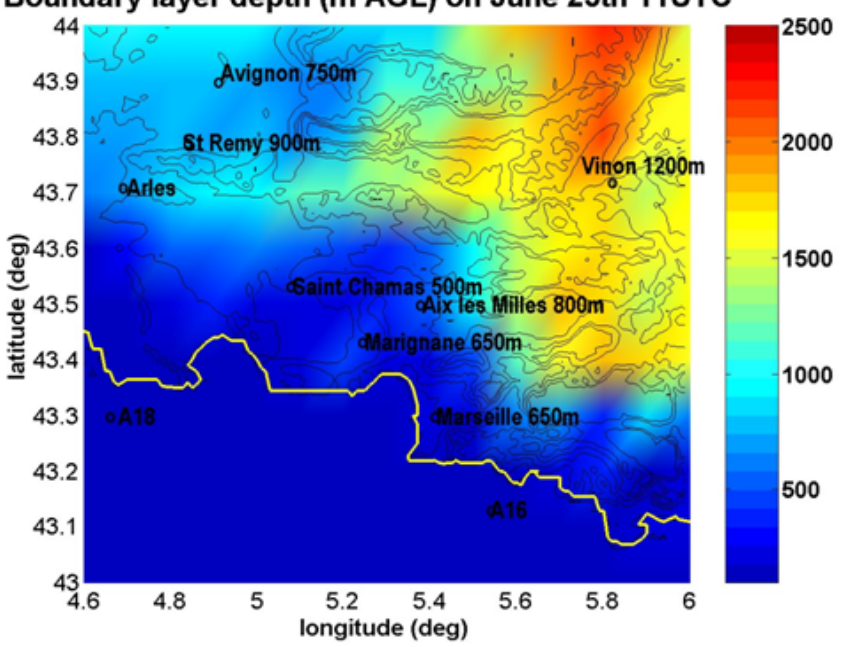

Boundary layer depth (m AGL) on June 26th 11UTC

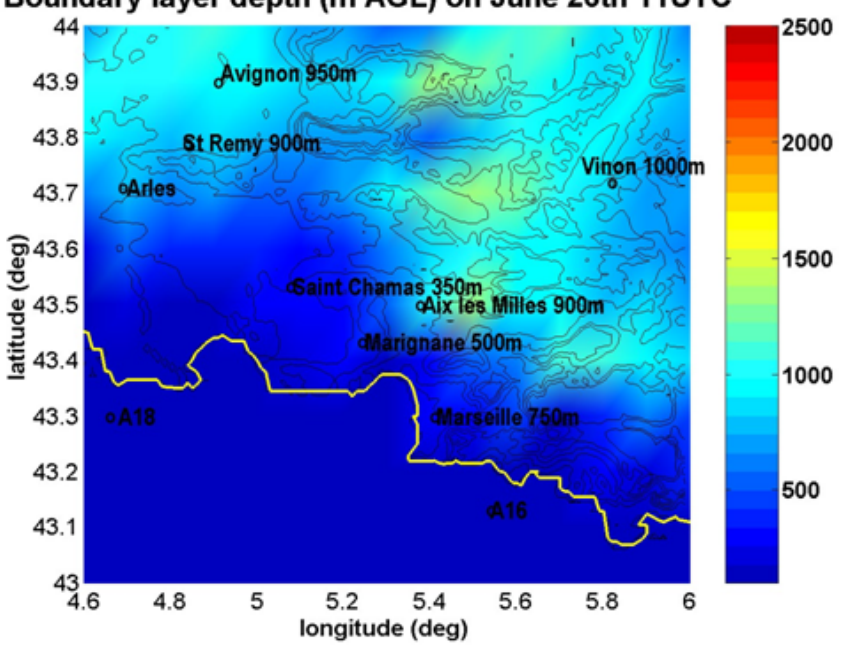

\section{Boundary layer depth (m AGL) on June 24th 14UTC}

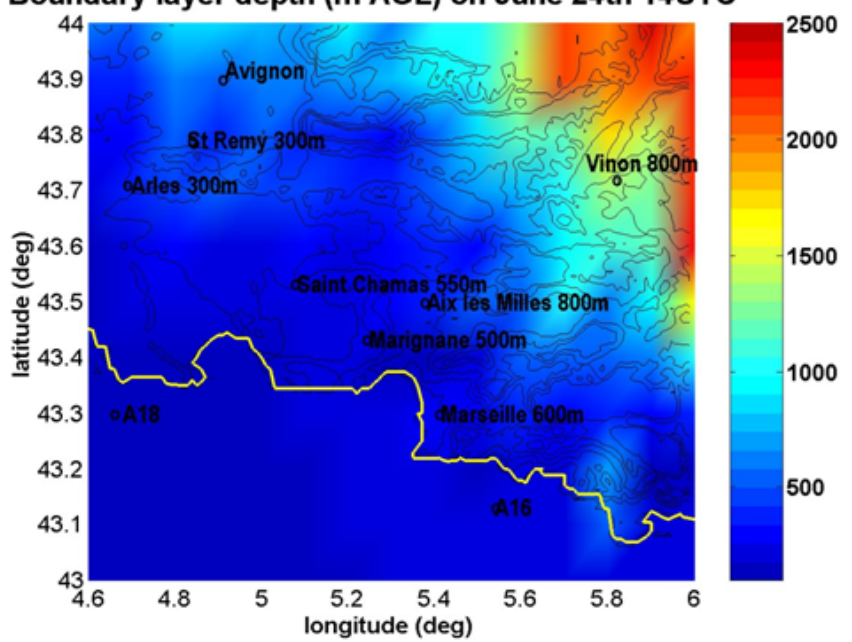

Boundary layer depth (m AGL) on June 25th 14UTC

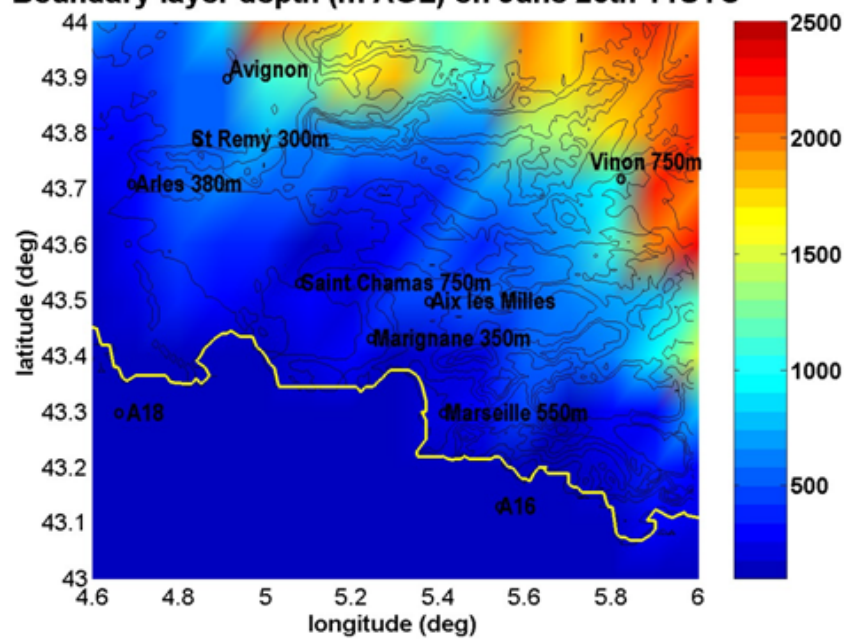

Boundary layer depth (m AGL) on June 26th 14UTC

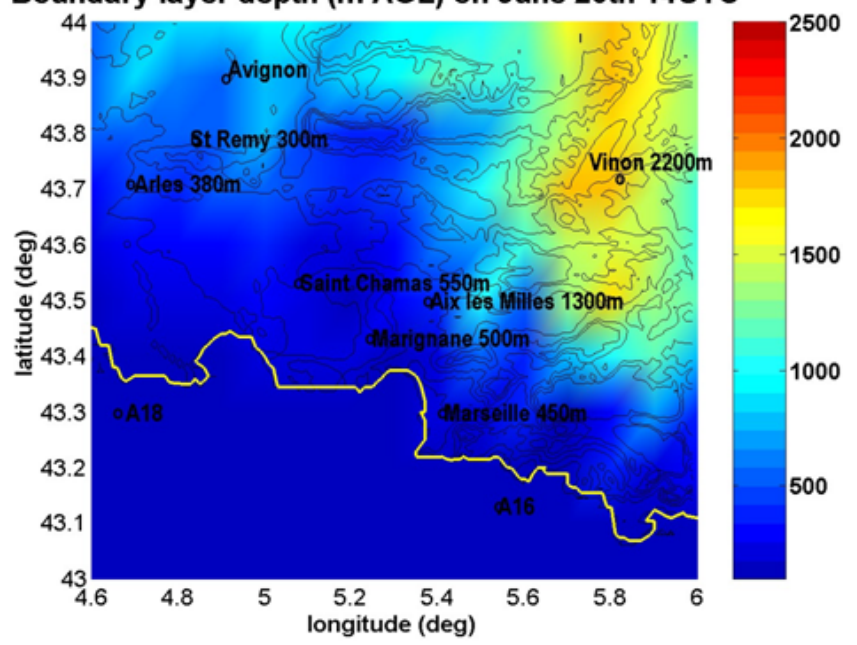

Fig. 14. Same as Fig. 13 for IOP2b. 


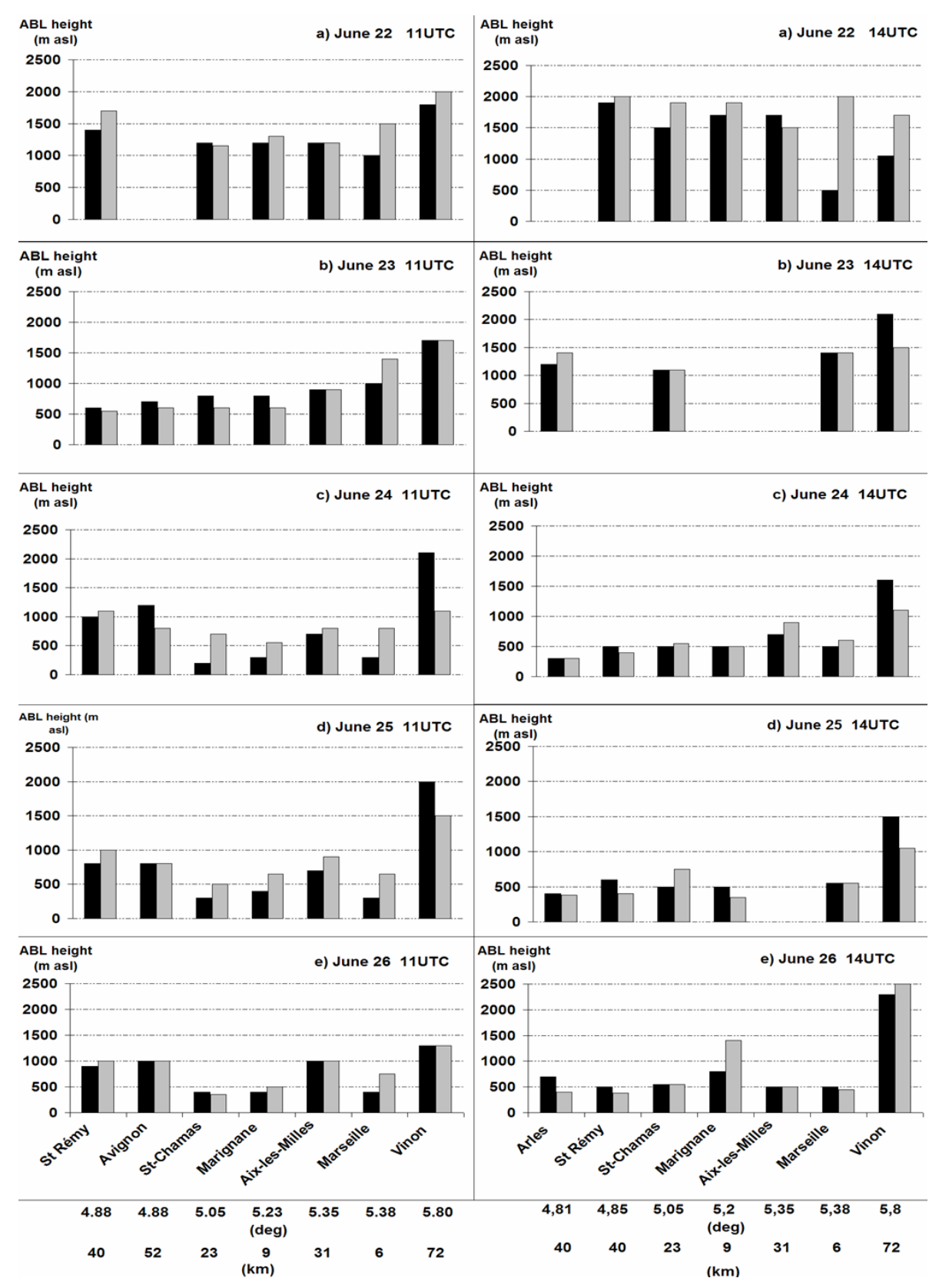

Fig. 15. Comparisons of the boundary layer height Zi (ASL) determined from the Meso NH model (black) and from experimental data (grey) at 11:00 UTC (left) and 14:00 UTC (right). Values of Zi in different places over the ESCOMPTE domain are presented for the whole IOP from J22 (a) to J26 (e). The various locations of the sites are indicated using their name, their longitude and their distance to the seashore.

over the mountain as over the plain. On J23, 14:00 UTC, the Mistral has weakened over the mountain $\left(5-7 \mathrm{~m} \mathrm{~s}^{-1}\right.$ instead of $8-12 \mathrm{~m} \mathrm{~s}^{-1}$ ) and the temperature difference has increased between the Rhône valley and the mountain, which favors the upslope circulation: the ABL develops preferentially over the mountainous part, reaching $2000 \mathrm{~m}$ in several places (Fig. 13).

\subsubsection{IOP2a - offshore advection of the ABL}

Also noticeable is the offshore extension of the continental ABL over the sea during this IOP. Figure 13 displays the apparent different behaviors of the ABL close to the coastline between both days: on $\mathrm{J} 22$, the continental ABL extends over the sea at 11:00 UTC. This is obvious on Fig. 13: the ABL is still high over the sea at the point A18, where the aircraft vertical sounding indicates that the ABL reaches 
$1400 \mathrm{~m}$. This is not reproduced by the model which simulates a sea-breeze penetration up to latitude $43.45 \mathrm{deg} \mathrm{N}$ at $4.7 \mathrm{deg}$ E. The sounding result is confirmed by the aircraft's horizontal field of the TKE dissipation rate $\varepsilon$ at $800 \mathrm{~m}$ (not shown here), which indicates strong turbulence at $800 \mathrm{~m}$ near the coast. So, instead of a sea-breeze penetration, there is an advection of the continental ABL over the sea which is capping the marine surface layer. The only place where the simulation accounts for this advection is in the Marseille bay at 11:00 UTC. At 14:00 UTC again, the model fails to represent it: for instance, the UHF radar indicates an ABL depth growing from $1500 \mathrm{~m}$ to $2000 \mathrm{~m}$ between 11:00 and 14:00 UTC in Marseille (Fig. 15; see also Fig. 8a for St Chamas), whereas the model simulates its decrease from 1000 to $500 \mathrm{~m}$ due to the sea-breeze penetration (see also Fig. 9a from Sect. 4.2). The model indicates a competition between the sea-breeze layer and Mistral (with no real development of any sea-breeze layer), whereas the observations show that Mistral is simply advected offshore, above the marine surface layer.

On J23, model and experience agree to display this offshore horizontal advection of the continental ABL (Figs. 13, 9b). In addition, the numerical field at 14:00 UTC displays a deepening of the ABL in the advected continental layer, supporting the results from Caccia et al. (2004), who showed that the Mistral is raised up by the sea breeze near the coast.

The important feature to keep in mind is that for both days, when the synoptic wind is counteracting the sea-breeze, the effect of the latter is to advect offshore and raise the continental layer. A well mixed layer of pollutants is transported over the sea. This layer is disconnected from the surface.

5.3.4 IOP2b - combination of various mesoscale circulations and consequence on the sea-breeze penetration

During IOP 2b, the synoptic flow is rather weak, which allows the sea-breeze onset. The latter is provoked by the high difference in horizontal temperature between the sea-surface and the continental surface. Puygrenier et al. (2005) presented the characteristics of the sea breeze measured in Marseille, in relationship with the horizontal surface temperature gradient between the sea and the continent: they indicated differences of $8^{\circ} \mathrm{C}, 7.7^{\circ} \mathrm{C}$ and $8.6^{\circ} \mathrm{C}$ for $\mathrm{J} 24, \mathrm{~J} 25$ and $\mathrm{J} 26$, respectively.

However, this temperature difference that could be linked to the breeze intensity in the case of a rectilinear coast and flat area, is not the prevalent parameter in the ESCOMPTE area. Another important parameter in this area of complex topography is the presence of up-slope breezes, induced by the temperature contrast between the Rhône valley and the Alps foothills. This circulation, which was described before at the scale of the Durance valley, also developed as a mesoscale circulation, linked to the strong west-east temperature gradient measured over the area: at 11:00 UTC, the west-east temperature gradient measured by the aircraft at $800 \mathrm{~m}$ is $3.5^{\circ} \mathrm{C}$, $3.5^{\circ} \mathrm{C}$ and $4^{\circ} \mathrm{C}$ for $\mathrm{J} 24,25$ and 26 , respectively. It is not significant at 14:00 UTC, since the $800-\mathrm{m}$ level is no longer inside the ABL but this gradient still exists at lower levels.

As a consequence, the wind measured over the ESCOMPTE area is the composition of moderate synoptic wind, with a sea breeze and up-slope breeze, i.e.:

- the end of the Mistral episode (north-westerly 6$8 \mathrm{~m} \mathrm{~s}^{-1}$ synoptic wind, according to the Dornier flight at $2800 \mathrm{~m}$, rapidly decaying in the $\mathrm{ABL}$ ), with a sea breeze (south component at mesoscale) and slope-wind (west component) on $\mathrm{J} 24$ : the result is a west moderate wind in the area at $800 \mathrm{~m}$, with a channeling effect (acceleration) in the west-east and south-north parts of the Durance valley at 11:00 UTC.

- the synoptic wind is still north-westerly $6-8 \mathrm{~m} \mathrm{~s}^{-1}$ and decays during the day, according to the Dornier flight and the radiosoundings. It is very weak within the ABL. The sea breeze is blowing from the south, as indicated by Bastin et al. (2005a, b) over the sea, with an up-slope breeze (west) on $\mathrm{J} 25$ which results in a weak, disorganized west, south-west wind, with again a channel effect in the Durance valley at 11:00 and 14:00 UTC (Fig. 11d).

- the synoptic wind is blowing from the south, southwest on $\mathrm{J} 26$. It is weaker at $2800 \mathrm{~m}$ than on the previous days $\left(5-6 \mathrm{~m} \mathrm{~s}^{-1}\right)$ but its decay is less important in the low layers. A sea-breeze is blowing from the south (Bastin et al., 2005) and an up-slope wind from the west. The real wind is not easy to observe on the aircraft fields which are at 11:00 UTC as at 14:00 UTC, measured in the transition area between the breeze and the synoptic flow. The only available information is from the French-German Doppler lidar wind measurements on board the Falcon 20. Bastin et al. (2005a) measured on J26 a weaker sea breeze than on J25 but a little stronger resulting flow, blowing from the south.

These differences in the flow characteristics have already been outlined by Bastin et al. (2005a), who emphasized the effect of flow acceleration in the Durance valley. They argue that the presence or absence of an onshore synoptic wind may also weaken or strengthen the sea breeze. For the three days of the sea breeze we studied, we highlight, in addition, the mesoscale gradient between the Rhône valley and the mountain which superimposes another mesoscale component to the flow. This component is essential to explain the strong development of the ABL over the mountainous area (and not only in the Durance valley). The other explanation to this strong development that is suggested by the simulation is the convergence area (also reported by Bastin et al., 2005a), generated over the mountain by two sea breezes (from the west near Marseille and from the east near Toulon), induced by the different orientations of the coast: this convergence area 
does not exist on the aircraft wind fields, so we discarded this argument.

The sea breeze and upslope wind act to reinforce each other: the stronger the sea breeze is in the Rhône valley, the cooler the temperature and the stronger the upslope wind is towards the mountains, which leads to drawing up the sea breeze along the mountain hills and into the Durance valley.

Keeping in mind the complexity of the flow, we are going to look now at the different behaviors of the ABL (Fig. 14). It clearly appears that near the coast, the ABL remains stuck close to the surface during the whole IOP $2 b$ and is lower than during the previous Mistral days. The sea breeze has inhibited the ABL development by advecting cooler air at the ground. Close to the coastline, typical values of $Z_{i}$ (heights and depths are the same near the coast) are estimated at $400 \mathrm{~m}$ with numerical simulations and are determined at 650to $800-\mathrm{m}$ with measurements. The main reason why the ABL do not develop is the strength of the inversions at the top of the ABL: Fig. 12 provides an illustration for this inversion on J25, where the lapse rate in Saint Rémy at 09:00 UTC is $9.5^{\circ} \mathrm{C} / 100 \mathrm{~m}$, whereas it is only 2.4 on $\mathrm{J} 22$. This huge lapse rate value is a characteristic of IOP $2 \mathrm{~b}$ : it is linked to the cooling of the lower layers due to the sea breeze and the warming of the air mass in altitude linked to the anticyclonic conditions.

On J24, the boundary layer remains particularly low over the whole area, except on the northeastern mountains. The Alpilles ridge near Saint Rémy is still inside the ABL at $800 \mathrm{~m}$, but Avignon is outside, which means that the sea breeze has already reached this area. In accordance with the westerly wind direction at 11:00 UTC, the sea breeze penetrates between the two ridges to the east to Aix les Milles (Sainte Victoire and Sainte Baume) but not in the Durance valley yet. Although these ABL fields are not aimed at determining the location of the sea-breeze front, the difference between the dark blue part between the 11:00 UTC and 14:00 UTC fields nicely accounts for the penetration of the sea-breeze inland north to the Avignon latitude (the depth is around $500 \mathrm{~m}$ near Avignon at 14:00 UTC). The sea breeze has also penetrated into the Durance valley, up to Vinon between 11:00 and 14:00 UTC (depth is $800 \mathrm{~m}$ ) (12:00 UTC in Meyrargues at the surface according to Table 1) but the ABL still remains high at 14:00 UTC over the mountain to the northeast.

The sea breeze is weaker on $\mathrm{J} 25$ since the temperature difference with the sea is weaker than on J24. So the southern part of the Alps foothill is not affected yet by the sea breeze at 11:00 UTC (although the onset occurred in Meyrargues at 10:00 UTC at the surface), and neither is the Alpilles area just south to Saint Rémy, where the ABL depth is $900 \mathrm{~m}$ (top at $1000 \mathrm{~m}$, as indicated on Fig. 16). At 14:00 UTC, the seabreeze has reached the Rhône valley (Avignon) and the Durance valley (Vinon) at the upper levels (Fig. 14), as reported by Bastin et al. (2005a) who indicate that the channeling in the Durance valley occurred at 13:00 UTC. At 14:00 UTC, the ABL in Vinon is only $800 \mathrm{~m}$, whereas it was $1200 \mathrm{~m}$ at 11:00 UTC.

On J26, the combination of sea breeze, slope wind and southwest synoptic wind induces a breeze onset at around 07:00 UTC in Marseille and La Crau, and 13:30 UTC in Meyrargues (Table 1), which is $1 \mathrm{~h}$ earlier than for the previous day in the first case, and $3 \mathrm{~h}$ later for the second. Bastin et al. (2005a) compared the sea-breeze onset between J25 and J26: they argue that the onshore winds on J26 bring cold marine air that inhibits the breeze onset. The mesoscale analysis of the sea-breeze by Bastin et al. (2005a) does not match our results at a smaller scale: in fact, the air temperature in the early morning is $2^{\circ} \mathrm{C}$ warmer in the Rhône valley on J26 than on J25. This corresponds to a synoptic increase in the temperature in the low troposphere and balances the fact that the onshore wind would have cooled the surface. On the other hand, the early morning air temperature gradient between the Rhône valley and the mountain is $3^{\circ} \mathrm{C}$ on $\mathrm{J} 25$, whereas it is only $1^{\circ} \mathrm{C}$ on $\mathrm{J} 26$. This may explain the time-shift of the seabreeze onset on $\mathbf{J} 26$, since the valley-mountain breeze is less efficient than it was on J25.

\subsubsection{IOP2b - strong ABL development above the moun- tains}

The depth of the ABL over the mountain, in the parts which are not affected by the sea breeze, like the Durance valley, is drastically different between IOP2b (J24 and 25 only) and IOP2a: although the model may emphasize this effect as written before, the ABL is most of the time deeper than $2000 \mathrm{~m}$ over the relief on $\mathbf{J} 24$ and 25 . This reflects the fact that in this case, thermal effects prevail over dynamics: as the wind is very weak, the up-slope breeze, due to the temperature difference between Rhône valley and mountains, is free to develop, and enhances the convection over the slopes. These results confirm those from Hasel et al. (2005), who remarked that the ABL does not always follow the height variation of the underlying surface, especially in the case of enhanced vertical mixing over the mountain. In these cases, the dynamic effect (constriction) pointed out over the Durance valley near Vinon is no longer visible.

The ABL depth is not deeper than $1800 \mathrm{~m}$ on $\mathrm{J} 26$ at 11:00 UTC (Fig. 15), even on the mountainous part, since the up-slope wind is not so efficient as in the previous days to raise the ABL. In Vinon, it grows between 11:00 UTC and 14:00 UTC from 1300 to $2500 \mathrm{~m}$, due to the constriction of the flow in the valley. There, the ABL is a superposition of an 800-m deep layer of southeast very weak wind inside the valley and a $1400-\mathrm{m}$ deep layer with west, south-west wind above (not shown here). This wind-shear at the height of the mountain surrounding Vinon is occurring on J25 and J26: it coincides with a discontinuity in humidity, showing a more moistened layer at the surface, corresponding to the sea-breeze layer on $\mathrm{J} 25$ and some marine air coming from the southeast on J26. However, no discontinuity is observed in 

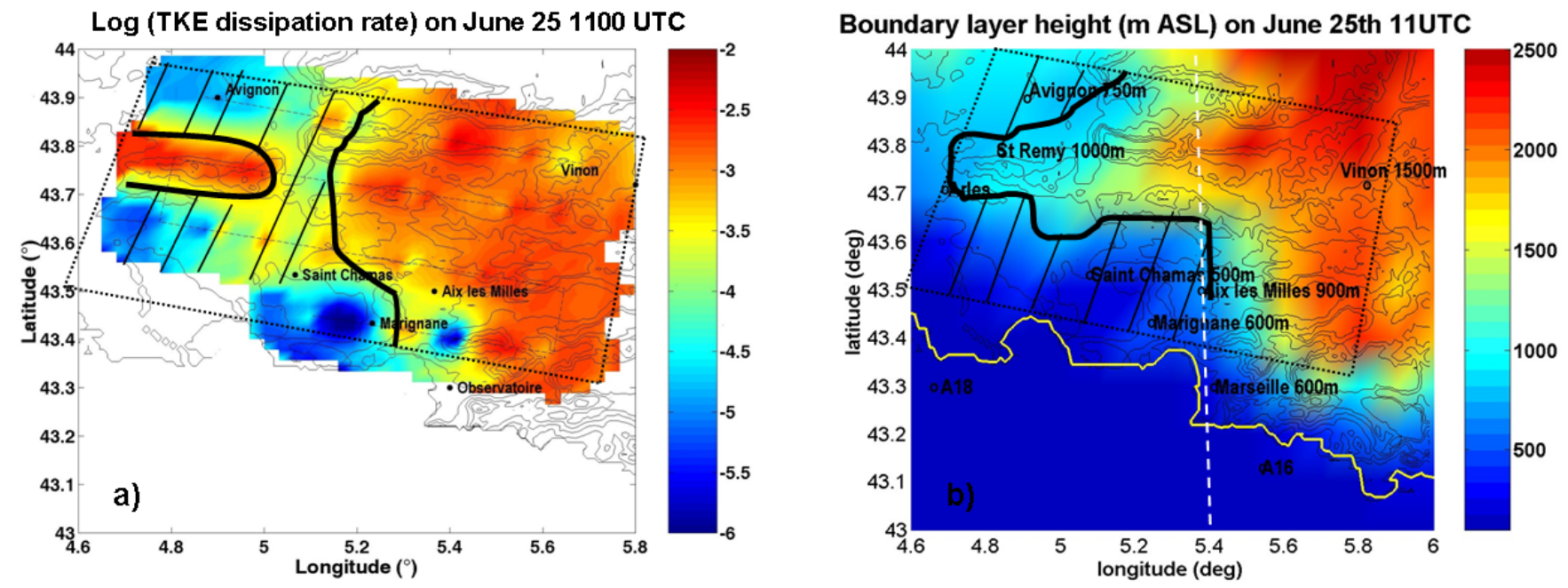

Fig. 16. Indirect validation of the boundary layer height estimated from the model: comparison with turbulence level provided by the aircraft measurements. (a): dissipation rate of turbulent kinetic energy (logarithmic scale). Strong values (orange and red) show that the aircraft flying at $800 \mathrm{~m}$ is inside the ABL, whereas it is outside when flying in the striped area. (b): ABL height estimated with the model. The 800-m height is delimited by the black solid line. The dashed white line refers to the location of the vertical cross section represented in Fig. 9.

the temperature profile. On J25, the sea-breeze layer matches the ABL (750 $\mathrm{m}$ deep); on $\mathrm{J} 26$, it is lower than the ABL ( $800 \mathrm{~m}$ for a $2200 \mathrm{~m}$ deep ABL). So specific circulation of the pollution is expected to occur in the valley, with air coming from the Aix-Marseille polluted area on J25 at low level, which is not the case on $\mathrm{J} 26$.

\section{Consequence on the plumes}

Our aim is now to analyze the impact of dynamics and boundary layer development on the transport and dilution of the plumes of a secondary pollutant such as ozone. Our study will be focused on the results at $800 \mathrm{~m}$, as a boundary between the ABL and the free troposphere. However, we previously saw that the $800-\mathrm{m}$ level is often situated above the ABL: in these cases, we will use the surface ozone concentrations obtained from the Meso-NH simulation to describe the plume.

6.1 Offshore advection, sea-breeze recirculation at low level and plume dilution over the mountain during IOP2a

During Mistral events in IOP2a, the ABL are deep and can be transported over the sea, which implies a dilution of the pollutants and an advection outside the inhabited areas. At 06:00 UTC on J22 (Fig. 17a), the plume, shown as blue areas of strong ozone titration, can be easily located at low levels downstream from the sources (Fos-Berre, Marseille, Aix). The Mistral strengthens over the sea due to the lower roughness of the surface and bends to the east, as reported in Bastin et al. (2005a), for J22, which favors the pollutants' evacuation over the sea but also keeps storage of pollution close to the coast. At the same hour at $800 \mathrm{~m}$ (Figs. 18a and $17 \mathrm{~d})$ the concentration is higher than at the surface: 50 to $60 \mathrm{ppbv}$ instead of 20-30. This background of pollution is not high in absolute. It corresponds to the concentration of the plume on the previous day (residual layer originated from the Rhône valley). At 11:00 UTC, photochemical processes have set up: most of the pollution simulated at the surface is coming from the Rhône valley (Fig. 17b) but the Berre area plume is distinct (60-65 ppbv around Saint Chamas, Marignane and Marseille). It does not extend far offshore. The concentration of the plume remains constant on the whole vertical column, downstream from the Rhône valley which is not affected by the sea breeze yet $(65 \mathrm{pbbv}$, as indicated by the aircraft sounding in A18, and by the Mesonh-C results at $800 \mathrm{~m}$ in Fig. 17e). It is not the case further to the east, where concentrations differ between surface and altitude over the sea due to the sea-breeze presence that maintains, close to the surface, a titration regime due to fresh NO coming from the Berre-Marseille polluted areas.

Another important result is the dilution of the plume over the mountainous part of the domain: this area is not influenced by the Rhône valley plume and the pollution generated by local sources is evacuated towards the sea. The ozone concentration remains very low at the surface as well as in altitude: $50-55 \mathrm{ppbv}$ at the ground (Fig. 17b) and at $800 \mathrm{~m}$ (Fig. 17e) for the model and $45 \mathrm{ppbv}$ for the aircraft (Fig. 18b). This is not surprising due to the larger depth of the boundary layer characterizing the area which favors pollution dilution. In addition, the strong development of the ABL over the mountains is likely to favor exchanges between the ABL and the free troposphere (which is not the case over 


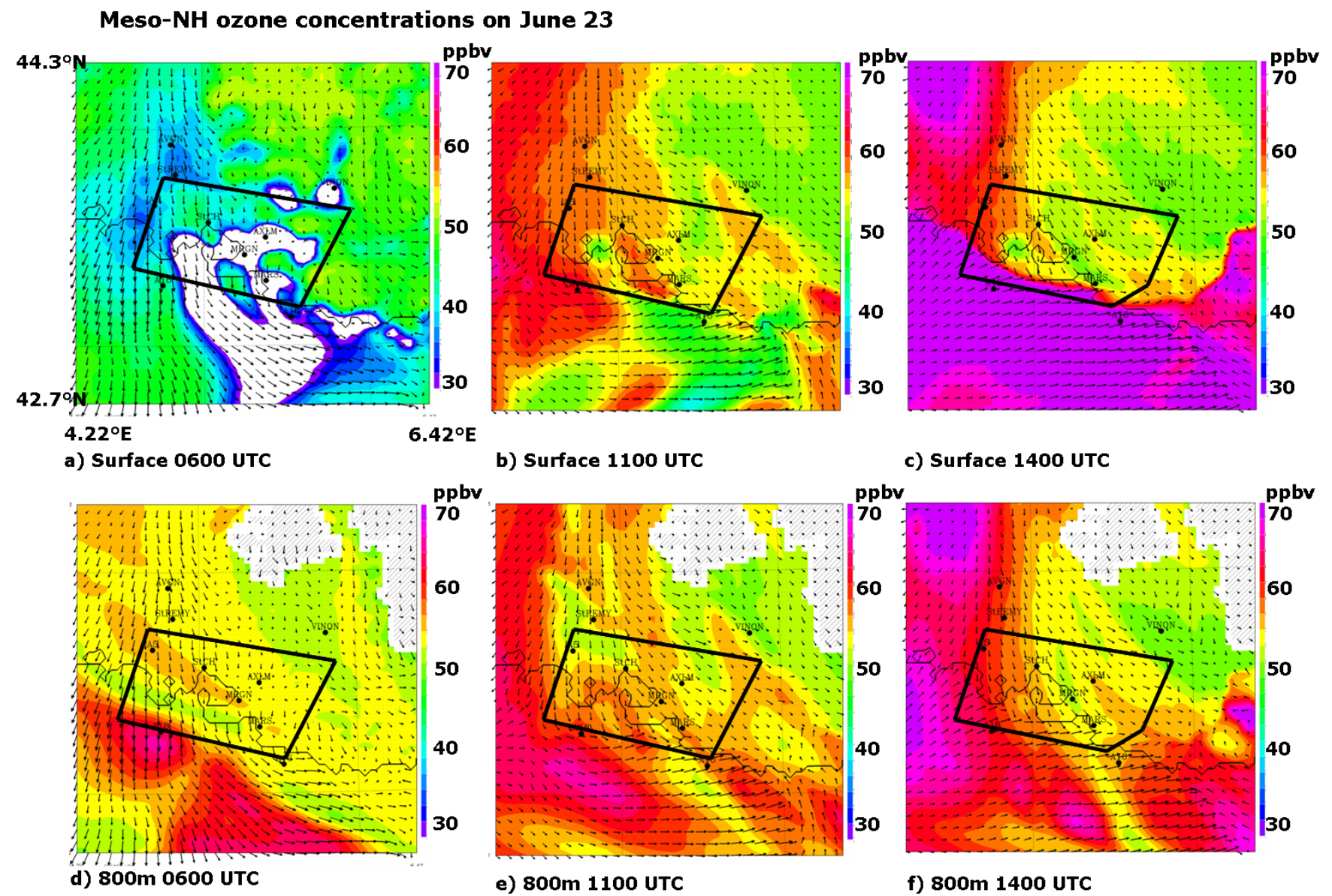

Fig. 17. Maps of ozone concentration (ppbv) simulated on 22 June at the ground (top) or at $800 \mathrm{~m}$ (bottom) at 06:00, 11:00 and 14:00 UTC with Meso-NH. The quadrilatere delimits the area flown over by the aircraft.

the Rhône valley, where the inversions capping the ABL are stronger, as seen before with Fig. 12). During IOP2a, the free troposphere is less polluted than the ABL. So the mixing above the mountains would have also contributed to the decrease in the ozone concentration.

Some higher local values can be observed in Marseille and Toulon (southeast to Fig. 18b), showing that the plume has surprisingly not been transported by the Mistral over the sea. Drobinski et al. (2007) argues from numerical results that on the first two days of IOP2, the pollutants accumulate near the coast after the sea breeze set-up and are injected at higher levels by the sea-breeze front. This is why the Marseille and Toulon plumes are still present in the vicinity of the sources at 11:00 and 14:00 UTC. Nevertheless, they remain very close to the coast. Note that the model ozone concentration is slightly underestimated at 14:00 UTC in this area: $57 \mathrm{ppbv}$ instead of 67.

\subsection{Inland transport of the pollution during IOP2b}

The anticyclonic conditions of IOP $2 b$, marked by high temperatures, favor high ozone production rates during the day (Cousin et al., 2005; Coll et al., 2005), in comparison with the moderate production rate of IOP2a. In addition, the low wind conditions prevent the evacuation of the pollution far from the sources. We will use in the following the results of $\mathbf{J} 25$, to characterize the plumes under sea-breeze conditions.

At 06:00 UTC on J25, titration generates again very low ozone concentrations at the surface (Fig. 19a): 10-20 ppbv. In altitude, the aircraft field indicates two areas of higher ozone concentration (Fig. 18; 80 ppbv), where the ozone accumulated the day before. At 11:00 UTC the low and cold sea-breeze layer is pushed inland towards the Rhône valley and the Durance valley. The boundary layer remains very low near the coast (Fig. 14). Pollutants do not remain in this layer in spite of the fast ozone production rates simulated near the emission areas: Coll et al. (2005) reported 60 to $80 \mathrm{ppbv} \mathrm{h}^{-1}$ in the early afternoon during the three days of IOP2b. These rates are twice as fast as those of IOP2a. 

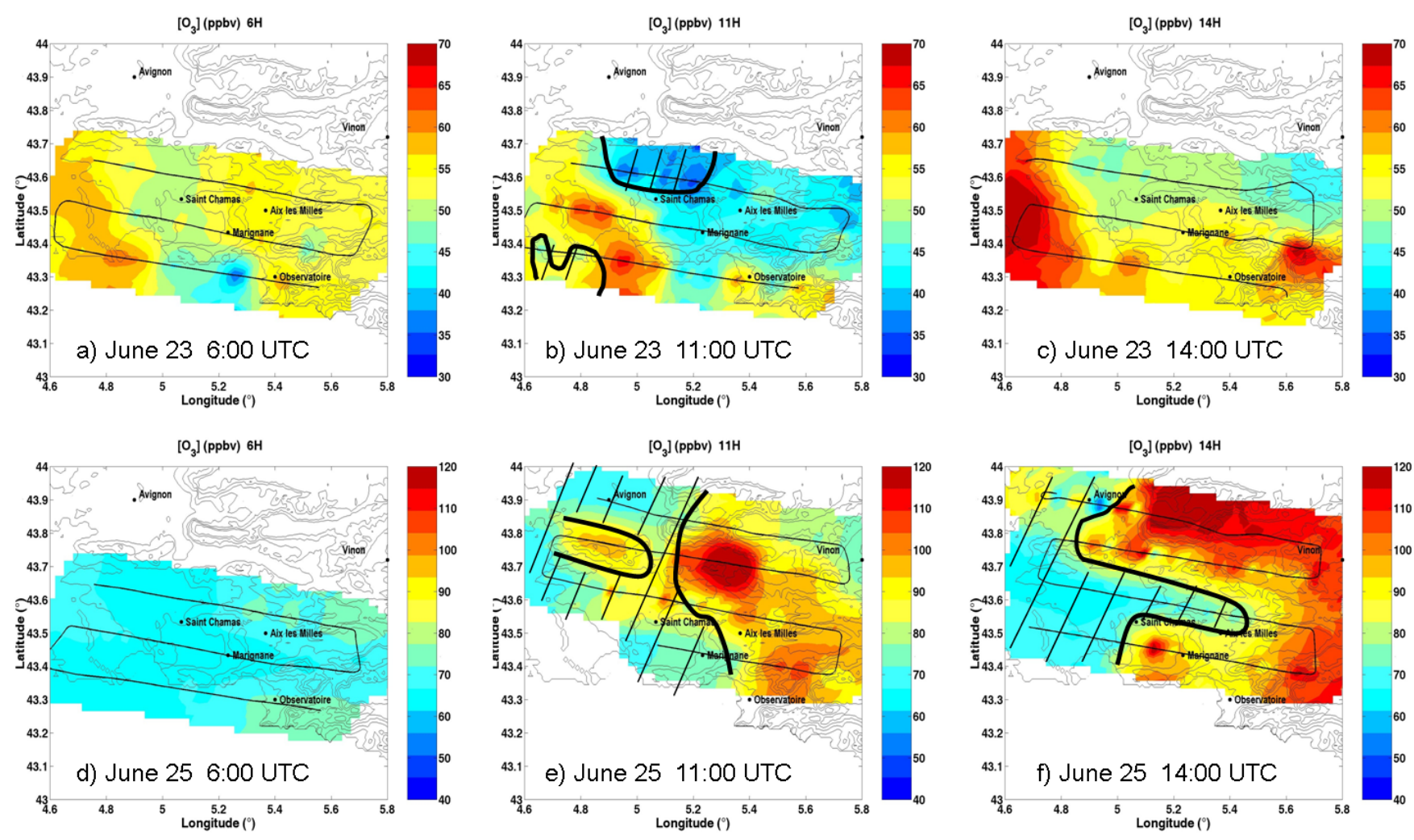

Fig. 18. Fields of ozone concentration (ppvb) measured by the aircraft at $800 \mathrm{~m}$, on 23 June (top) and 25 June (bottom), at 00:06, 11:00 and 14:00 UTC. The dashed areas were flown over above the boundary layer.

In fact, the plume is pushed inland by the sea breeze and on the relief by the slope breezes. Between 10:00 UTC and 13:00 UTC, the production rates reach 50 to $80 \mathrm{ppbv} \mathrm{h}^{-1}$ in the plume, about $50 \mathrm{~km}$ downwind from the sources (Coll et al., 2005). The plume ozone concentration is not higher than $60 \mathrm{ppbv}$ near the coast at the surface (Fig. 19b). The pollution is transported into the Rhône and Durance valley and over the mountains, far from the sources $(90 \mathrm{ppbv}$ in Figs. 19b and c). This is even more marked at $800 \mathrm{~m}$, where the Marseille and Fos-Berre plumes can first be distinguished at 11:00 UTC (Fig. 18e: 105 and $120 \mathrm{ppbv}$ ), whereas they merge in a large plume, with very high ozone concentrations (120 ppbv) which staggers over the mountain at 14:00 UTC (Fig. 18f). At this time, the production rates have dropped (Coll et al., 2005), so the high ozone concentrations measured on the relief have been produced earlier and transported over the mountain. There again, the model underestimates the ozone concentration (90 ppbv between Avignon and Vinon instead of 120).

Since the boundary layer top is higher in the northeastern part of the ESCOMPTE domain, due to up-slope circulations induced by the mountains, it is not excluded that vertical exchanges with the free troposphere occur in this area during IOP2b.
This situation is clearly reproduced on the other days of IOP2b: the ozone plume is $120 \mathrm{ppbv}$ over the mountains. In agreement with what was said in Sect. 5, the plume does not penetrate so far over the mountains on J26 as on the previous days (not shown).

So, in summary, IOP2b, which is well representing summer episodes of pollution in southeastern France, is characterized by inland transport of pollution from the source areas to the mountains under sea-breeze and slope-breeze effects.

\section{Conclusions}

The ESCOMPTE experiment provided, with IOP2, the possibility to study two characteristic summer situations of the region: a case when pollution was evacuated offshore, not far from the coast and brought back to the emission area, and a case of pollution transport inland, far from the sources.

A wide range of experimental means were operated during the campaign: the large data set collected during the experiment allowed for the validation of the simulations with the Meso-NH model at 3-km resolution. Thus, the comparison of dynamical and thermo-dynamical parameters showed very good agreement. To study the structure of the boundary layer, maps of boundary layer depths have been built. They 

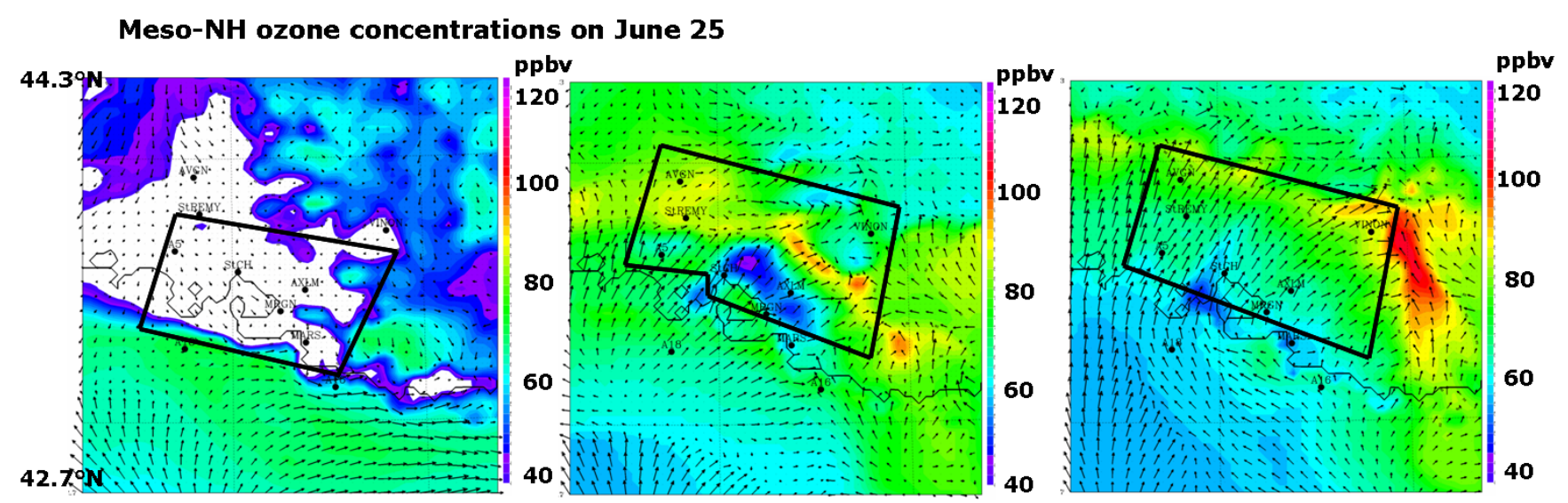

$4.22^{\circ} \mathrm{E}$

a) Surface 0600 UTC

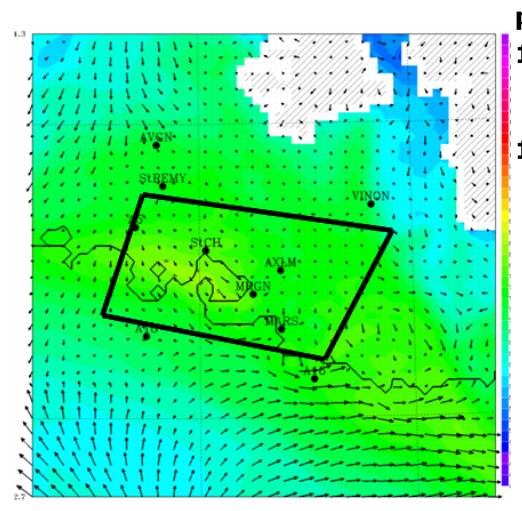

d) $800 \mathrm{~m} 0600$ UTC $6.42^{\circ} \mathrm{E}$

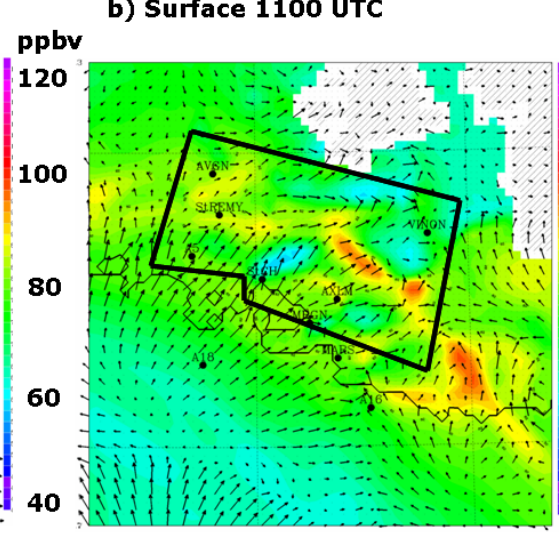

e) $800 \mathrm{~m} 1100$ UTC c) Surface 1400 UTC

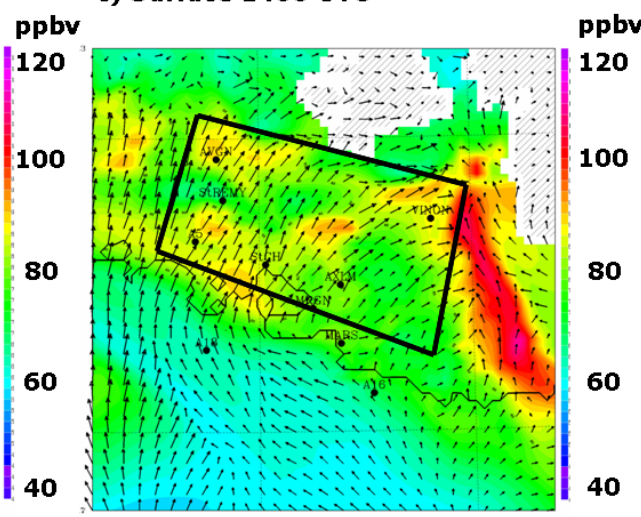

f) $800 \mathrm{~m} 1400$ UTC

Fig. 19. Same as Fig. 17 for 25 June.

enabled us to provide, with accuracy, the depth of the layer where pollutants may accumulate or be diluted. There again, the simulation results were consistent with the observations. On the contrary, the model was not very good at reproducing the concentration of a secondary pollutant, such as ozone, and sometimes could display an approx. 30-ppbv underestimation.

The main results that were underlined in the study were the following:

- sea breeze and moderate Mistral (synoptic wind) were in competition during the first two days which prevented the sea breeze from developing: deep boundary layers were formed and extended offshore over the marine surface layer. The air mass was not greatly polluted on these days (60-70 ppbv). The Rhône valley pollution was evacuated over the sea while the Fos-BerreMarseille pollution remained offshore close to the coast and was brought back to the littoral by the sea breeze.

- due to the weaker synoptic wind, the sea breeze and slope breeze occurred during IOP2b. The boundary layers were capped by strong inversions at their top near the coast and inside the Rhône and Durance valley and remained very low. The boundary layers were deeper over the mountains due to slope-wind effects. Weak concentrations of ozone were measured in the sea-breeze layer and the plume was transported up to the mountains where $120 \mathrm{ppbv}$ were observed.

- the complexity of the topography implied very specific developments driven by mesoscale parameters, such as sea-land and valley-mountain temperature differences. These thermodynamic effects are reduced in the presence of a moderate synoptic wind: the sea breeze does not penetrate so far inland and the up-slope winds do not generate very deep ABL on the mountains. Local circulations (downtown Marseille, for instance) or constrictions effects inside the Durance valley are also important factors which modulate the ABL development.

- these results would require generalization with the other ESCOMPTE IOPs but IOP2b is definitively well representative of summer severe pollution episodes in southeastern France. 
- the nice boundary development during IOP2a or over the mountain during IOP2b is likely to favour the exchanges between the mixed layer and the free troposphere. Evidence was given by Cousin et al. (2005) and Drobinski et al. (2007) that aged pollution layers coming from remote areas are stacked above the ESCOMPTE ABL. Kalthoff et al. (2005) made local estimations of entrainment and detrainment processes over the mountain and the Rhône valley. However, Bastin et al. (2006) argue that detrainment does not compensate vertical export in the free troposphere linked to up-slope and sea-breeze winds. This should deserve further investigation and especially an accurate computation of the budget at the top of the ABL, to calculate the sign of the exchanges.

Acknowledgements. We would like to thank ADEME, INERIS and CNRS who supported this work. We are also very grateful to Institut für Meteorologie und Klimaforschung and more especially to U. Cormseier, N. Kalthoff and Ch. Kottmeier, who provided the radiosounding data as well as airborne data of Dornier 128. We also thank the Centre National de Recherches Météorologiques team from Météo-France and P. Bouchou, A. Fotiadi and D. Serça from Laboratoire d'Aérologie for providing the Vallon D'ol, Crau and Meyrarargues ground data. This study wouldn't have been completed without their help. We finally thank C. Lafleur and Y. Gratton who freely provide their kriging software on the web.

Topical Editor F. D'Andrea thanks two referees for their help in evaluating this paper.

\section{References}

Angevine, W. M., White, A. B., and Avery, S. K.: Boundary layer depth and entrainment zone characterization with a boundary layer profiler, Boundary-layer Meteorol., 68, 375-385, 1994.

Angevine, W. A., Trainer, M., McKeen, S. A., and Berkowitz, C. M.: Mesoscale meteorology of the New England coast, gulf of Maine, and Nova Scotia: Overview, J. Geophys. Res., 101(D22), 28 893-28 901, 1996.

Angevine, W. M., Senff, C. J., White, A. B., Williams, E. J., Koermer, J., Miller, S. T. K., Talbot, R., Johnston, P. E., McKeen, S. A., and Downs, T.: Coastal boundary layer influence on pollutant transport in New England, J. Appl. Meteorol., 43, 1425-1437, 2004.

Bastin, S., Drobinski, P., Guenard, V., Caccia, J. L., Campistron, B., Dabas, A., Delville, P., Reitebuch, O., and Werner, C.: On the interaction between the sea-breeze and a summer Mistral event at the exit of the Rhône valley, Mon. Wea. Rev., 134, 1647-1667, 2006.

Bastin, S., Drobinski, P., Dabas, A., Delville, P., Reitebuch, O., and Werner, C.: Impact of the Rhône and Durance valleys on seabreeze circulation in the Marseille area, Atmos. Res., 74, 303328, 2005a.

Bastin, S., Champollion, C., Bock, O., Drobinski, Ph., and Masson, F.: On the use of GPS tomography to investigate water vapor variability during a Mistral/sea-breeze event in southeastern France, Geophys. Res. Lett., 32(5), doi:10.1029/2004GL021907, 2005b.
Brut, A., Legain, D., Durand, P., and Laville, P.: A Relaxed Eddy Accumulator for surface flux measurements on ground-based platforms and aboard research vessels, J. Atmos. Oceanic Technol., 21(3), 411-427, 2004.

Bernard-Trottolo, S., Campistron, B., Druilhet, A., Lohou, F., and Saï, F.: TRAC98: Detection of coherent structures in a convective boundary layer using airborne measurements, Bound. Layer Meteorol., 111, 181-224, 2004.

Caccia, J. L., Guénard, V., Benech, B., Campistron, B., and Drobinski, P.: Vertical velocity and turbulence aspects during Mistral events as observed by UHF wind profilers, Ann. Geophys., 22, 3927-3936, 2004, http://www.ann-geophys.net/22/3927/2004/.

Coll, I., Pinceloup, S., Perros, P., Laverdet, G., and Le Bras, G.: $3 \mathrm{D}$ analysis of high ozone production rates observed during the Escompte campaign, Atmos. Res., 74, 477-505, 2005.

Corsmeier, U., Behrendt, R., Drobinski, Ph., and Kottmeier, Ch.. The mistral and ist effect on air pollution transport and vertical mixing, Atmos. Res., 74, 275-302, 2005.

Cousin, F., Tulet, P., and Rosset, R.: Interaction between local and regional polluted layers in the low troposphere: impact on surface ozone concentrations during ESCOMPTE 2001, IOP2, Atmos. Res., 74, 117-137, 2005.

Crassier, V., Suhre, K., Tulet, P., and Rosset, R.: development of a reduced chemical scheme for use in mesoscale meteorological models, Atmos. Environ., 34, 2633-2644, 2000.

Cros, B., Durand, P., Cachier, H., Drobinski, Ph., Fréjafon, E., Kottmeier, C., Perros, P. E., Peuch, V.-H., Ponche, J.-L., Robin, D., Saïd, F., Toupance, G., and Wortham, H.: The ESCOMPTE program: an overview, Atmos. Res., 69, 241-279, 2004.

Delbarre, H., Augustin, P., Saïd, F., Campistron, B., Bénech, B., Lohou, F., Puygrenier, V., Moppert, C., Cousin, F., Fréville, P., and Fréjafon, E.: Ground-Based remote sensing observation of the complex behaviour of the Marseille boundary layer during ESCOMPTE, Atmos. Res., 74, 403-433, 2005.

Deutsch, C. V. and Journel, A. G.: GSLIB: Geostatistical Software Library and User's Guide, Oxford University Press, Oxford, 340 p, 1992.

Drobinski P., Saïd, F., Ancellet, G., Augustin, P., Bastin, S., Brut, A., Caccia, J. L., Campistron, B., Cautenet, S., Colette, A., Coll, I., Corsemeier, U., Cros, B., Dabas, A., Delbarre, H., Durand, P., Dufour, A., Guénard, V., Hasel, M., Kalthoff, N., Kottmeier, C., Lasry, F., Lemonsu, A., Lohou, F., Masson, V., Menut, L., Moppert, C., Peuch, V. H., Puygrenier, V., Reitbuch, O., and Vautard, R.: Regional transport and dilution during high pollution episodes in southern France: Summary of findings from the ESCOMPTE experiment, J. Geophys. Res., in press, 2007.

Gangoiti, G., Millàn, M. M., Salvador, R., and Mantilla, E.: Longrange transport and re-circulation of pollutants in the western Mediterranean during the project REgional Cycles of Air Pollution in the west-central Mediterranean Area, Atmos. Environ., 35, 6267-6276, 2001.

Garratt, J. R.: The internal boundary layer - a review, Cambridge Bound. Layer Meteorol., 50, 171-203, 1990.

Guénard, V., Drobinski, P., Caccia, J. L., Campistron, B., and Benech, B.: An observational study of the Mistral mesoscale dynamics, Boundary Layer Meteorol., 115(2), 263-288, 2005.

Gheusi, F., Cammas, J. P., Cousin, F., Mari, C., and Mascart, P.: Quantification of mesoscale transport across the boundaries of 
the free troposphere: a new method and applications to ozone, Atmos. Chem. and Phys. Discuss., 4, 8103-8139, 2004.

Hasel, M., Kottmeier, Ch., Corsmeier, U., and Wieser, A.: Airborne measurements of turbulent trace gas fluxes and analysis od eddy structure in the convective boundary layer over complex terrain, Atmos. Res., 74, 381-402, 2005.

Heo, B. K., Jacoby-Koaly, S., Kim, K. E., Campistron, B., Bénech, B., and Jung, E. S.: Use of the Doppler spectral width to improve the estimation of the convective boundary layer height from UHF wind profiler observations, J. Atmos. Ocean. Technol., 20, 408424, 2003.

Jacoby-Koaly, S., Campistron, B., Bernard, S., Bénech, B., Girard, F., Dessens, J., Dupont, E., and Carissimo, B.: turbulent dissipation rate in the boundary layer via UHF wind profiler Doppler spectral width measurement, Bound. Layer Meteorol., 103, 361389, 2002.

Kalthoff, N., Kottmeier, C., Thürauf, J., Corsmeier, U., Saïd, F., Fréjafon, E., and Perros, P. E.: Mesoscale circulation systems and ozone concentrations during ESCOMPTE: a case study from IOP2b, Atmos. Res., 74, 355-380, 2005.

Lafleur, C. and Gratton, Y.: http://globec.whoi.edu/software/ kriging/V3/intro_v3.htm, 1998.

Lafore, J. P., Stein, J., Asencio, N., Bougeault, P., Ducrocq, V., Duron, J., Fischer, C., Hereil, P., Mascart, P., Masson, V., Pinty, J. P., Redelsperger, J. L., Richard, E., Vila-Guerau de Arellano, J.: The Meso-NH atmospheric simulation system. Part I: adiabatic formulation and control simulations, Ann. Geophys., 16, 90-109, 1998 http://www.ann-geophys.net/16/90/1998/.

Lambert, D. and Durand, P.: The marine atmospheric boundary layer during SEMAPHORE. Part1: mean vertical structure and non-axisymmetry of turbulence, Quart. J. Roy. Meteorol. Soc., 125, 495-512, 1999.

Lemonsu, A., Bastin, S., Masson, V., and Drobinski, P.: Vertical structure of the Urban Boundary Layer of Marseille under Sea-Breeze Conditions, Bound. Layer. Meteorol., 118, 477-501, 2006.

Lenschow, D. H. and Stankov, B. B.: Length scales in the convective Boundary Layer, J. Atmos. Sci., 43(12), 1198-1209, 1986.

Marcotte, D.: Cokrigeage with MATLAB, Computers \& Geosciences, 17(9), 1265-1280, 1991.

Matheron, G.: Principles of geostatistics, Economic Geology, 58, 1246-1266, 1963.

Mestayer, P. G., Durand, P., Augustin, P., Bastin, S., Bonnefond, J.-M., Bénech, B., Campistron, B., Coppalle, A., Delbarre, H., Dousset, B., Drobinski, P., Druilhet, A., Fréjafon, E., Grimmond, C. S. B., Groleau, D., Irvine, M., Kergomard, C., Kermadi, S., Lagouarde, J.-P., Lemonsu, A., Lohou, F., Long, N., Masson, V., Moppert, C., Noilhan, J., Offerle, B., Oke, T. R., Pigeon, G., Puygrenier, V., Roberts, S., Rosant, J.-M., Saïd, F., Salmond, J., Talbaut, M., and Voogt, J.: The urban boundary-layer field campaign in marseille (ubl/clu-escompte): set-up and first results, Bound. Layer Meteorol., 114, 315-365, 2005.
Millàn, M., Salvador, R., Mantilla, E., and Artiñano, B.: Meteorology and photochemical air pollution in southern Europe: experimental results from EC research projects, Atmos. Environ., 30, 1909-1924, 1996.

Millàn, M., Salvador, R., Mantilla, E., and Kallos, G.: Photooxidant dynamics in the Mediterranean basin in summer: results from European research projects, J. Geophys. Res., 102(D7), 88118823, 1997.

Millàn, M., Mantilla, E., Salvador, R., Carratala, A., Sanz, M. J., Alonso, L., Gangoiti, G., and Navazo, M.: Ozone cycles in the western Mediterranean basin: interpretation of monitoring data in complex coastal terrain, J. Appl. Meteorol., 4, 487-507, 2000.

Puygrenier, V., Lohou, F., Campistron, B., Saïd, F., Pigeon, G., Benech, B., and Serça, D.: Investigation of the fine structure of sea-breeze during the ESCOMPTE experiment, Atmos. Res., 74, 329-353, 2005.

Rosenthal, J. S., Helvey, R. A., Battalino, T. E., Fisk, C., and Greiman, P. W.: Ozone transport by mesoscale and diurnal wind circulations across southern California, Atmos. Environ., 37(2), 51-71, 2003.

Saïd, F., Corsmeier, U., Kahltoff, C., Kottmeier, N. C., Lothon, M., Wieser, M., Hofherr, T., and Perros, P.: ESCOMPTE experiment: intercomparison of four aircraft dynamical, thermodynamical, radiative and chemical measurements, Atmos. Res., 74, 217-252, 2005.

Shaw, W. J. and Businger, J. A.: Intermittency and the organization of turbulence in the near-neutral marine Atmospheric Boundary Layer, J. Atmos. Sci., 42(23), 2563-2584, 1985.

Stull, R. B.: An introduction to Boundary Layer Meteorology, Kluwer Academic Publishers, Dordrecht, 666 p, 1988.

Suhre, K., Mari, C., Bates, T. S., Johnson, J. E., Rosset, R., Wang, Q., Bandy, A. R., Blake, D. R., Eisele, F. L., Kok, G. L., Mauldin III, R. L., Prévot, A., Schillawski, R. D., and Thornton, D. C.: Physico-chemical modeling of the First Aerosol Characterisation Experiment (ACE-1) Lagrangian B. 1. A moving column approach., J. Geophys. Res., 103, 16 433-16455, 1998.

Vogel, B., Fiedler, F., and Vogel, H.: Influence of toppography and biogenic volatile compounds emission in the state of BadenWürttemberg on ozone concentrations during episodes of high air temperatures, J. Geophys. Res., 100, 22 907-22 928, 1995.

Wickert, B., Schwarz, U., Blank, P., John, C., Kuhlwein, J., Obermeier, A., and Friedrich, R.: Generation of an Emission Data Base for Europe 1994, Proc. Eurotrac Symposium 98, 2, 255 265, 1999. 